\title{
NONLINEAR ERROR CORRECTION: THE CASE OF MONEY DEMAND IN THE UNITED KINGDOM (1878-2000)
}

\author{
Alvaro Escribano \\ Universidad Carlos III de Madrid, Spain
}

This paper explores single-equation nonlinear error correction (NEC) models with linear and nonlinear cointegrated variables. Within the class of semiparametric NEC models, we use smoothing splines. Within the class of parametric models, we discuss the interesting properties of cubic polynomial NEC models and we show how they can be used to identify unknown threshold points in asymmetric models and to check the stability properties of the long-run equilibrium. A new class of rational polynomial NEC models is also introduced. We found multiple long-run money demand equilibria. The stability observed in the money-demand parameter estimates during more than a century, 1878 to 2000 , is remarkable.

Keywords: Money Demand, Nonlinear Error Correction, Cubic Polynomials, Rational Polynomials, Smoothing Splines, Nonlinear Cointegration

\section{INTRODUCTION}

Single-equation error correction (EC) models were originally proposed by Phillips (1954, 1957). However, Sargan (1964) represents the first important empirical EC application, which was extended later to the UK consumption function by Davidson et al. (1978); see Hendry and Richard (1983). In the context of linear cointegrated variables, Engle and Granger (1987) suggested a two-step OLS estimator of EC models and a unit root test for testing the null hypothesis of non-cointegration based on the application of the Dickey-Fuller test to the residuals of the OLS cointegrating regression. Stock (1987) found the asymptotic distribution of the one-step nonlinear least-squares (NLS) estimator of EC models. Since then, there has been a vast

\footnotetext{
This paper was presented in the First Annual Meeting of the European Science Foundation Network on "Econometric Methods for Modelling of Nonstationary Data, Policy Analysis and Forecasting," Varese, Italy, September 19-21, 2002. The author acknowledges financial support from the Spanish grant BEC2002-00279 and the European Union grant HPRN-CT-2002-00232 and wishes to thank an anonymous referee, Karim Abadir, Rob Engle, Neil Ericsson, Clive Granger, David Hendry, and Santiago Mira for making useful comments and suggestions in previous versions of this paper. Special thanks go to Neil Ericsson and David Hendry for their help in getting the information for updating the database until 2000 with the excellent research assistance of Lorena Sáiz. Address correspondence to: Alvaro Escribano, Department of Economics, Universidad Carlos III de Madrid c/ Madrid 126, Madrid 28903, Spain; e-mail: alvaroe@eco.uc3m.es.
} 
body of econometric literature comparing the two approaches; see for example, Banerjee et al. (1986, 1993), Gonzalo (1994), Hendry (1995), and Johansen (1995).

Johansen (1992) considers the efficiency of the one-step maximum likelihood estimation procedure of linear EC models based on weakly exogenous variables. On the other hand, Phillips and Hansen (1990), Phillips (1991), Phillips and Loretan (1991), and Marmol et al. (2002) study alternative efficient least-squares and instrumental variables estimators, always within a linear cointegration context.

In standard EC models with cointegrated variables, the corresponding EC adjustment (equilibrium correction ${ }^{1}$ ) is linear. This important linearity property imposes at least three strong restrictions on the underlying economic behavior:

(i) The long-run equilibrium is unique.

(ii) The adjustment toward the equilibrium (equilibrium correction) is symmetric.

(iii) The equilibrium correction is a constant proportion of the previous equilibrium error.

However, there are good theoretical and empirical reasons to believe that the linearity property of the equilibrium correction is too restrictive. For example, the existence of asymmetric adjustment costs of the inputs (labor, capital, etc.) of the firms implies the existence of asymmetric EC models; see Escribano and Pfann (1998). It is also natural to believe that the equilibrium corrections could be business-cycle dependent, implying that those adjustments are not constant proportions of previous equilibrium errors. Finally, there is a large amount of empirical evidence of regime shifts in linear models. This has an alternative interpretation, based on the well-known result that nonlinear models can sometimes be approximated by linear models with regime shifts. The advantage of the class of nonlinear error correction (NEC) models that we introduce in this paper is that it can easily encompass those three properties.

The seminal NEC model was introduced and applied to money demand in the United Kingdom (1878 to 1970) by Escribano (1985, 1986). Later, Hendry and Ericsson (1991) were able to combine this nonlinear (cubic polynomial) error correction with other suggestions of Longbottom and Holly (1985) and then produced a better specification of the UK money demand that encompasses the previous ones. Latter, Ericsson et al. (1998) extended the money demand analysis until the year 1993, incorporating an interesting measure of opportunity cost of holding money.

In this paper, we give sufficient conditions to characterize single-equation NEC models with linear cointegrated variables (representation theorem) using the results of Escribano and Mira (2002). Furthermore, we propose an econometric methodology to specify the nonlinear equilibrium correction terms, which is based on parametric (ordinary least-squares or nonlinear least-squares) and semiparametric (smoothing splines) estimation procedures.

Previous parametric NEC models have used cubic polynomial adjustments, which are unbounded and therefore provide no warrantee that the adjustment toward the equilibrium is stable (equilibrium correction). Therefore, in this paper, 
we introduce the class of rational polynomials and show that they can generate unbounded, but stable, adjustments toward the equilibrium (or equilibria) while mimic king most of the nice, flexible features of cubic polynomials.

The structure of the paper is as follows. In Section 2, we characterize NEC models with linear cointegrated variables, within the context of parametric nonlinear models. On the basis of Padé approximants we justify the generality of rational polynomial NEC models. In Section 3.1, we reproduce the main aspects of the unpublished semiparametric EC models discussed by Escribano (1986, ch. 4 ) in the context of the smoothing-spline estimators. In Section 3.2, we briefly review the asymptotic properties of the two-step least-squares estimation procedure of parametric NEC models. In Section 3.3, we introduce the preliminary analysis that can be done to identify NEC terms. In Section 4, we briefly review the three main unpublished and competing original UK money demand estimates (1878-1970) of Hendry and Ericsson (1983), Longbottom and Holly (1985), and Escribano (1985, 1986). In Section 4.1, we implement the econometric methodology suggested in Section 3 to specify NEC models with the seminal applications to the money demand in the UK (1878-1970). In Section 4.2, we briefly evaluate Hendry and Ericsson's (1991) and Ericsson et al.'s (1998) money demand equations. In Section 5, we extend the money demand estimates of Ericsson et al. (1998) from the year 1993 to the year 2000. Cubic and rational polynomial NEC models are estimated and evaluated during the extended period and a brief discussion on nonlinear cointegration is included. Finally, in Section 6 we present the main conclusions.

\section{COINTEGRATION AND NONLINEAR ERROR CORRECTION}

In this section, we introduce some useful concepts of time-series that are integrated of order 0 and $1, I(0)$ and $I(1)$, and we characterize the concept cointegration in the context of NEC models. The problem of introducing nonlinearities in nonstationary contexts is nontrivial since the concepts of integration and cointegration are based on linear time-series frameworks.

In general, the concept of $I(1)$ is related to time-series variables that need to be differenced once to become covariance-stationary, $I(0)$. Therefore, given a finite starting value, the partial sum of an $I(0)$ process is $I(1)$ since their variance and covariance grow over time. The basic idea now is to extend the usual concepts of $I(0)$ processes to allow for certain types of heteroskedasticity and nonlinearities of the underlying sequences. To do that we use nonlinear measures of short-run dependence; see Davidson (1994).

For example, the concept of $\alpha$-mixing introduced by Rosenblatt (1978), measures dependence between events that are separated by at least $m$ periods (leads and lags). Another useful measure for the degree of temporal dependence in a timeseries is based on the concept of near epoch dependence (NED); see Appendix A. Say that the coefficient $\phi_{m}$ is a measure of the worst mean square prediction error 
of $v_{t}$ based on the present, near past, and near future of $\eta_{t}, E\left(v_{t} / \eta_{t-m}, \ldots, \eta_{t+m}\right)$. If the sequence is $\phi-\mathrm{NED}$, then the worst conditional mean square prediction error tends to zero as $m \rightarrow \infty$.

The concepts of $\alpha$-mixing and NED are used now to define operative definitions of $I(0)$ and $I(1)$ in a nonlinear context, following Escribano and Mira (2002).

DEFINITION 1. The sequence $\varepsilon_{r t}$ is said to be $I(0)$ if it is an $\alpha$-mixing sequence $\left(\phi-N E D\right.$ on the underlying $\alpha$-mixing sequence $\left.v_{r t}\right)$ and the partial sum $x_{r t}=\sum_{i=1}^{t} \varepsilon_{r i}$ is not $\alpha$-mixing (is not $\phi$-NED). We then say that $x_{r t}=\sum_{i=1}^{t} \varepsilon_{r i}$ is $I(1)$.

Let $\varepsilon_{r 0}=0$. Notice that from Definition 1 if $x_{r t}$ is $I(1)$, then $\Delta x_{r t}$ is $I(0)$. Furthermore, if $\varepsilon_{r t}$ is $I(-1)$, then the partial sum $x_{r t}=\sum_{i=1}^{t} \varepsilon_{r i}$ is an $\alpha$-mixing sequence $\left(\phi\right.$-NED on the underlying $\alpha$-mixing sequence $v_{r t}$ ) and therefore not $I(1)$. In Section 3.2, we use these concepts to discuss the asymptotic distribution of the two-step least-squares estimator of NEC models.

The concepts of $I(0)$ based on $\alpha$-mixing or $\phi$-NED are related to the notions of "short memory in distribution" and "short memory in mean" discussed by Granger and Teräsvirta (1993) and Granger (1995). Our broad concept of $I(0)$ has the clear advantage of having laws of large numbers (LLN) and functional central-limit theorems (FCLT) associated with them; see, for example, White (1984), Herrndorf (1984), Phillips (1987), Gallant and White (1988), Wooldridge and White (1988), Davidson (1994) and Dufrénot and Mignon (2002).

On the basis of those concepts, Escribano and Mira (1996) found the asymptotic distribution of the nonlinear least-squares (NLS) estimator of the nonlinear cointegrating relationship.

Let the $N \times 1$ vector $\boldsymbol{X}_{t}$ be equal to $\left(y_{t}, q_{t}^{\prime}\right)^{\prime}$, where $y_{t}$ is an escalar and $q_{t}$ is an $(N-1) \times 1$ vector. $^{2}$

The following concept of cointegration is convenient for Theorem 1.

DEFINITION 2 (COINTEGRATION). If $y_{t}$ and $q_{t}$ are I(1) and there is a linear combination, $z_{t} \equiv y_{t}-\alpha^{\prime} q_{t}$, that is $\alpha$-mixing (or correspondingly $\phi$-NED) for the parameters $\left(1, \alpha^{\prime}\right)$ and is not $\alpha$-mixing (or $\phi$-NED) for any other vector $\left(1, \alpha^{*^{\prime}}\right)$ with $\alpha^{\prime} \neq \alpha^{*^{\prime}}$, then $y_{t}$ and $q_{t}$ are cointegrated with cointegrating vector $\left(1,-\alpha^{\prime}\right)$.

This definition can easily cover cases of nonlinear cointegration if we allow $z_{t} \equiv g\left(y_{t}-\alpha^{\prime} q_{t}\right)$ in Definition 2. The concept of $I(0)$ for $\phi$-NED sequences is now used, instead of the asymptotic uncorrelation condition used by Escribano (1987), to properly characterize single-equation NEC models based on the representation theorem of Escribano and Mira (2002). The objective of Theorem 1 is to give sufficient conditions for NEC models to imply cointegration (Granger-type representation theorem).

THEOREM 1 (SINGLE-EQUATION NEC REPRESENTATION THEOREM). Let the $N \times 1$ vector $\boldsymbol{X}_{t}=\left(y_{t}, q_{t}^{\prime}\right)^{\prime}$, where $y_{t}$ is a scalar and $q_{t}$ is the $(N-1) \times 1$ vector be generated by 


$$
\begin{gathered}
\Delta y_{t}=b_{0}^{\prime} \Delta q_{t}+b_{1}^{\prime} \Delta q_{t-1}+\cdots+b_{r}^{\prime} \Delta q_{t-r}+a_{1} \Delta y_{t-1}+\cdots+a_{p} \Delta y_{t-p} \\
+f\left(z_{t-1}, \gamma\right)+\varepsilon_{y t}, \\
\Delta q_{t}=\varepsilon_{q t}, \\
z_{t} \equiv y_{t}-\alpha^{\prime} q_{t},
\end{gathered}
$$

where

(i) $\varepsilon_{y t}$ is a martingale difference sequence relative, to the information generated by the explanatory variables $\left(X_{t-1}\right)$ observed up to time $t-1$, with zero mean, constant variance, $\sigma^{2}$, and the $(N-1) \times 1$ vector $\varepsilon_{q t}$ is $\alpha$-mixing with constant variancecovariance matrix, $\Sigma$;

(ii) the determinantal equation $\left|1-a_{1} B-a_{2} B^{2}+\cdots+a_{p} B^{p}\right|=0$ has all its roots outside the unit circle;

(iii) the function $f(z, \gamma)$ is continuously differentiable on $z$;

(iv) and $-2<d f\left(z_{t-1}, \gamma\right) / d z_{t-1}<0$ (stability condition)

(v) $\Delta q_{t}, \varepsilon_{y t}$ and the cross products have finite second-order moments.

Then,

(a) $\boldsymbol{X}_{t}$ is a vector of $I(1)$ components and

(b) $z_{t}$ and $\Delta X_{t}$ are $\phi-N E D$ and therefore $y_{t}$ and $q_{t}$ are cointegrated with cointegrating vector $\left(1,-\alpha^{\prime}\right)$.

Proof. See Appendix A.

In Theorem 1, we show that when there is an NEC model like (1a), if the stability condition (iv) is satisfied, then under some regularity conditions the first difference of the variables, $\Delta X_{t}$, must be $I(0) ; y_{t}$ and the levels of some (or all) of the $q_{t}$ variables are cointegrated; and $z_{t}=y_{t}-\alpha^{\prime} q_{t}$ (some but not all of the components of $\alpha$ could equal to 0 ).

Notice that when the maximum lags $r$ and $p$ are equal, and when certain common factor restrictions (COMFAC) are satisfied [see Hendry and Mizon (1978)], $b_{0}^{\prime}-$ $\alpha^{\prime}=0, b_{1}^{\prime}-a_{1} \alpha^{\prime}=0, \ldots, b_{p}^{\prime}-a_{p} \alpha^{\prime}=0$, we can write the NEC-equation (1a)—in terms of $z_{t}$ :

$$
\Delta z_{t}=a_{1} \Delta z_{t-1}+\cdots+a_{p} \Delta z_{t-p}+f\left(z_{t-1}, \gamma\right)+\varepsilon_{y t} .
$$

This nonlinear autoregressive process, $\operatorname{AR}(p+1)$, for $z_{t}$ is a nonlinear extension of the augmented Dickey-Fuller (ADF) equation used by Engle and Granger (1987) to test the null hypothesis of unit roots (noncointegration) against roots lower than unity (cointegration). With the NEC models [equation (2)], the null hypothesis of noncointegration $\left[\left(z_{t}, I(1)\right)\right]$ implies that $H_{0}: f\left(z_{t-1}, \gamma\right)=0$ whereas, under the alternative hypothesis of cointegration $\left(\mathrm{z}_{t}, \phi\right.$-NED), $H_{1}: f\left(z_{t-1}, \gamma\right) \neq 0$ with $-2<d f(z, \gamma) / d z<0$.

Escribano $(1985,1986)$ suggested the use of cubic polynomials for $f\left(z_{t-1}, \gamma\right)=$ $\sum_{i=1}^{3} c_{i} z^{i}$ since polynomials can approximate general nonlinear functions based 
on Taylor-series expansions. However, a first-order autoregressive cubic polynomial representation for $z_{t}$ cannot globally satisfy the useful $\phi$-NED condition of Escribano and Mira $(1997,2002),-1<\left(d z_{t} / d z_{t-1}\right)<1$, since polynomials are unbounded and explosive functions for large values of $z_{t-1}$.

To solve the instability problem of polynomial approximations for large values of $z_{t-1}$, we suggest the class of time-series models based on low-order rational polynomial functions that globally satisfy the stability condition (iv) of Theorem 1 , while avoiding the three undesirable properties (i)-(iii) of linear EC models mentioned in the introduction. This property will become clear in the empirical application of Section 5.

Among the many nonlinear parametric functional forms to consider for $f(z, \gamma)$, there is a also a sound argument in favor of rational polynomial functional forms based on Padé approximants. The argument goes as follows: Assume that the function $f(z, \gamma)$ can be written as a power series; then, Padé's approximant is the rational fraction

$$
\{L / M\}=\left(d_{0}+d_{1} z+d_{2} z^{2}+\cdots+d_{L} z^{L}\right) /\left(1+e_{1} z+e_{2} z^{2}+\cdots+e_{M} z^{M}\right),
$$

which has a Maclaurin expansion that agrees with the power-series expansion. In total, we have $L+M+1$ unknown coefficients in (3). The rational fraction, $\{L / M\}$, should fit the power series so that

$$
\begin{gathered}
f(z, \gamma)=\sum_{i=1}^{\propto} c_{i} z^{i}=\left(d_{0}+d_{1} z+d_{2} z^{2}+\cdots+d_{L} z^{L}\right) \\
/\left(1+e_{1} z+e_{2} z^{2}+\cdots+e_{M} z^{M}\right)+O\left(z^{L+M+1}\right) .
\end{gathered}
$$

Power series have a circle of convergence $|z|=R$. If $|z|<R$, the series converges; if $|z|>R$, it diverges. When $R=\infty$, the function is analytic. The following version of Montessus's theorem [see Baker and Graves-Morris (1996)] gives a general approximation result.

THEOREM 2 (CONVERGENCE OF PADÉ APPROXIMANTS). Let $f(z, \gamma)$ be a function that is analytic at the origin and analytic in the entire z-plane except for a countable number of isolated poles and essential singularities. Suppose $\varepsilon>0$ and $\delta>0$ are given. Then, $M_{0}$ exists such that any $\{L / M\}$ Padé approximant of the ray sequence with $L / M=\lambda(\lambda \neq 0 \lambda \neq \propto)$ satisfies

$$
|f(z, \gamma)-\{L / M\}|<\varepsilon, \text { for any } M \geq M_{0},
$$

on any compact set of the z-plane except for a set of measures less than $\delta$.

Proof. See Appendix A.

However, we argue in this paper that cubic polynomial functional forms are very useful and flexible parametric approximations to unknown functional forms. The first justification is based on the simulation results obtained with Lagrange 
multiplier (LM) tests, when testing the null hypothesis of linearity against the alternative of nonlinearity; see, for example, Tsay (1986) and Escribano and Jorda (2001). Second, cubic polynomial approximations can be used as decision rules for selecting nonlinear parametric time-series models. Teräsvirta (1994) and Escribano and Jorda $(1999,2001)$ discussed the use of this type of LM tests when selecting between logistic and exponential smooth-transition autoregressive (STAR) models and between logistic and exponential smooth-transition regression (STR) models, respectively. Third, cubic polynomials can be used to detect asymmetries (linear or nonlinear) and threshold points (unique equilibrium or multiple equilibria); see Escribano and Pfann (1998). Fourth, they can be used to empirically check the stability condition ( $\phi$-NED condition) of the nonlinear adjustment, $f(z, \gamma)$; see condition (iv) of Theorem 1.

In the empirical applications discussed in Sections 4 and 5, we show how to use the flexibility of cubic polynomial functional forms in the context of NEC models.

\section{SPECIFICATION, ESTIMATION, AND TESTING IN NEC MODELS}

One of the main advantages of using the concepts of $I(1), I(0)$, and cointegration defined in the previous section is that they allow us to check whether an estimated NEC model satisfies those conditions. This is so because we give explicitly sufficient conditions on the nonlinear function.

On the other hand, to make the broad concepts of $I(1)$ and $I(0)$ introduced in Definition 1 testable we could add extra conditions in the manner of Phillips (1987) and Lo (1991).

Assumption 1.

(i) Let $v_{t}$ be $I(0)$ and $\alpha$-mixing so that the sequence of partial sums $y_{t}=\sum_{i=1}^{t} v_{i}$ is $I(1)$;

(ii) $E\left(v_{t}\right)=0$, for all $t$;

(iii) $\sup E\left|v_{t}\right|^{\beta}<\infty$, for some $\beta>2$;

(iv) $\sigma^{2}=\lim _{T \rightarrow \alpha} E\left(T^{-1} y_{T}^{2}\right)<\infty$, with $0<\sigma^{2}<\infty$;

(v) $\sum_{m=1}^{\infty} \alpha_{m}^{1-2 / \beta}<\infty$, where the $\alpha_{m}$-mixing coefficient is defined in Appendix A.

On the basis of Assumption 1, Herrndorf (1984) proved the following FCLT: $T^{-1 / 2}\left(\sum_{i=1}^{[T r]} v_{i}\right) \rightarrow \sigma W(\cdot)$ where $W(\cdot)$ is a standard Brownian motion.

Lo (1991) suggested the use of the test statistic $T^{-1 / 2} Q_{T}$ :

$$
\begin{aligned}
& Q_{T}=\left(1 / \sigma_{T}(s)\right)\left\{\max _{1 \leq k \leq T} \sum_{i=1}^{k}\left(v_{i}-\mu_{T}\right)-\min _{1 \leq k \leq T} \sum_{i=1}^{k}\left(v_{i}-\mu_{T}\right)\right\}, \\
& \sigma_{T}^{2}(s)=(1 / T) \sum_{i=1}^{T}\left(v_{i}-\mu_{T}\right)^{2}+(2 / T) \sum_{i=1}^{s}(1-i /(s+1)) \\
& \times \sum_{i=j+1}^{k}\left(v_{j}-\mu_{T}\right)\left(v_{j-i}-\mu_{T}\right),
\end{aligned}
$$


where $\mu_{T}$ and $\sigma_{T}^{2}(s)$ are the estimated mean and variance of $v_{t}$, and the optimal value of $s$ is obtained as the integer value of $K_{T}$, where $K_{T}=(3 T / 2)^{1 / 3}(2 \rho /(1-$ $\left.\rho^{2}\right)^{2 / 3}$.

Under the null hypothesis, $H_{0}: v_{t}$ satisfies Assumption 1, Lo (1991) derived the nonstandard asymptotic distribution of the test statistic $T^{-1 / 2} Q_{T}$.

Kwiatkowski et al. (1992) used a different test statistic to test the same null hypothesis $\left(H_{0}\right)$,

$$
\operatorname{KPSS}_{T}=\left(1 / \sigma_{T}^{2}(s)\right)\left(1 / T^{2}\right) \sum_{t=1}^{T} y_{t}^{2},
$$

where $y_{t}=\sum_{i=1}^{t}\left(v_{i}-\mu_{T}\right)$ and $\sigma_{T}^{2}(s)$ is given by (6b). The values of $s$ that they consider are $s=0, s=\left(4(T / 100)^{1 / 4}\right), s=\left(12(T / 100)^{1 / 4}\right)$, and the optimal value of $s$ previously mentioned (integer value of $K_{T}$ ).

Using the statistics $T^{-1 / 2} Q_{T}$ and $\operatorname{KPSS}_{T}$, we could test the null hypothesis, $H_{0}$ : $v_{T}$ is $I(0)$ and satisfies Assumption 1 against the alternative $H_{1}: v_{T}$ is $I(1)$ and/or does not satisfy Assumption 1.

Similarly, we could use the same test statistics to test the hypothesis of $I(0)$ versus $I(1)$ based on $\phi$-NED $v_{t}$ sequences, provided that they satisfy a FCLT. Wooldridge and White (1988) gave explicit conditions for a FCLT to hold under NED conditions; see also Davidson (1994).

\subsection{Semiparametric Approach}

Before we describe the semiparametric estimation procedure of NEC models based on somoothing splines, it is convenient to rewrite model (1a) as

$$
\Delta y_{t}=f\left(z_{t-1}, \gamma\right)+\Delta Q_{t}^{\prime} b+\Delta Y_{t-1}^{\prime} a+\varepsilon_{y t},
$$

where $\Delta Q_{t}^{\prime}=\left(\Delta q_{t}^{\prime}, \Delta q_{t-1}^{\prime}, \ldots, \Delta q_{t-r}^{\prime}\right)$ is a $1 \times(\mathrm{N}-1) r$ vector and $\Delta Y_{t-1}^{\prime}=$ $\left(\Delta y_{t-1}, \ldots, \Delta y_{t-p}\right)$ is a $1 \times p$ vector of lagged dependent variables, and $b$ and $a$ are the parameter vectors of orders $r(N-1) \times 1$ and $p \times 1$, respectively.

When the sample size is $T+h, t=-h, \ldots, T$ with $h=\max (r, p)$, model (8) in matrix notation becomes

$$
\Delta y=f\left(Z_{-1}, \gamma\right)+\Delta Q b+\Delta Y a+\varepsilon_{y},
$$

where $\Delta y=\left(\Delta y_{1}, \ldots, \Delta y_{T}\right)^{\prime}, f\left(Z_{-1}, \gamma\right)=\left(f\left(z_{0}, \gamma\right), \ldots, f\left(z_{T-1}, \gamma\right)\right)^{\prime} \quad$ and $\varepsilon_{y}=\left(\varepsilon_{y 1}, \ldots, \varepsilon_{y T}\right)^{\prime}$ are $T \times 1$ vectors, $\Delta Q=\left(\Delta Q_{1}, \ldots, \Delta Q_{1-r}\right)$ is a matrix of order $T \times(N-1) r$ and $\Delta Y=\left(\Delta Y_{-1}, \ldots, \Delta Y_{-p}\right)$ a matrix of order $T \times P$.

Our objective is to estimate the unknown nonlinear equilibrium correction, $f\left(Z_{-1}, \gamma\right)$, by the semiparametric procedure of smoothing splines. Spline smoothing is a very flexible estimation technique. The first analysis of their statistical properties for nonperiodic nonlinear functions appeared in Wahba (1975) and Silverman (1985). Different empirical applications of this estimation procedure are in Granger et al. (1984), Engle et al. (1986), and Härdle and Linton (1994). 
The smoothing-splines estimator that we use in the empirical section is obtained using the following procedure. Substitute equation (9) by a general parametric approximation,

$$
\Delta y=\chi_{-1} \beta+\Delta H \phi+\varepsilon_{y},
$$

where $f\left(Z_{-1}, \gamma\right) \approx \chi_{-1} \beta, \Delta H=(\Delta Q, \Delta Y)$ and $\phi=\left(b^{\prime} a^{\prime}\right)^{\prime}$. In this approximation $\chi_{-1}$ is a $T \times K$ matrix of zeros and ones and $k \leq T$ is the number of intervals into which the domain of the function has been divided. The matrix $\chi_{-1}$ is formed by reading each of the $T$ observations of $z_{t-1}$ and assigning the value 1 to the interval where the observation lies and 0 in the rest of the intervals. To estimate a smooth function, while avoiding overfitting the data, we can impose a smoothing penalty. To do that explicitly, we will first write equation (10) as

$$
\Delta y=W \delta+\varepsilon_{y},
$$

where $W=\left(\chi_{-1}, \Delta H\right)$ and $\delta=\left(\beta^{\prime}, \phi^{\prime}\right)^{\prime}$. The estimator of $\delta$ is obtained by minimizing the following objective function:

$$
\operatorname{Min}_{\delta}\left(\varepsilon_{y}^{\prime} \varepsilon_{y}+\lambda \delta^{\prime} V^{\prime} V \delta\right),
$$

where the matrix $V$ is chosen so that the smoothing constraint applies, in a direct way, only to the parameter vector $\beta$. Let $V=(B, 0)$, where $B$ is a $K \times K$ matrix and 0 is a $K \times L$ matrix where $L=(N-1) x r+p$; hence,

$$
\varepsilon_{y}^{\prime} \varepsilon_{y}+\lambda \delta^{\prime} V^{\prime} V \delta=\varepsilon_{y}^{\prime} \varepsilon_{y}+\lambda \beta^{\prime} B^{\prime} B \beta .
$$

The first component is the usual error sum of squares and the second represents the penalty imposed for lack of smoothness. The content of the matrix $B$ determines what type of smoothing constraints we want to impose. If, following the idea of smoothing splines, we impose a penalty based on the second derivative of the function $f(z, \gamma)$, then, when the intervals are of equal size, the matrix $B$ will be formed so that three adjacent $\beta^{\prime}$ s are close to a straight line, $\beta_{i+1}+\beta_{i-1}-2 \beta_{i}=0$; see Engle et al. (1986) for the treatment of a more general case.

The solution to the optimization problem (12) is

$$
\delta(\lambda)=\left(W^{\prime} W+\lambda V^{\prime} V\right)^{-1} W^{\prime} \Delta y,
$$

which, in a more explicit form, can be written as

$$
\delta(\lambda)=\left[\begin{array}{cc}
\chi_{-1}^{\prime} \chi_{-1}+\lambda B^{\prime} B & \chi_{-1}^{\prime} \Delta H \\
\Delta H^{\prime} \chi_{-1} & \Delta H^{\prime} \Delta H
\end{array}\right]^{-1}\left[\begin{array}{c}
\chi_{-1}^{\prime} \Delta y \\
\Delta \mathrm{H}^{\prime} \Delta y
\end{array}\right]
$$

The estimator $\delta(\lambda)$ is, under some regularity conditions, consistent but biased. The size of the bias of $\delta(\lambda)$ depends positively on the value of the parameter $\lambda$. On the other hand, the variance decreases with $\lambda$ getting the classical trade-off between bias and efficiency. 
To ascertain what the optimal value of $\lambda$ should be, Wahba (1975) developed the generalized cross-validation (GCV) procedure. This procedure chooses the value of $\lambda$ that solves

$$
\operatorname{Min}_{\lambda} \operatorname{GCV}(\lambda)=\operatorname{RSS}(\lambda) /(1-\operatorname{trace}(\mathrm{G}(\lambda) / \mathrm{T}))^{2},
$$

where $\operatorname{RSS}(\lambda)=(\Delta y-\Delta \hat{y})^{\prime}(\Delta y-\Delta \hat{y}), \Delta \hat{y}$ is the fit and $G(\lambda)=W\left(W^{\prime} W+\right.$ $\left.\lambda V^{\prime} V\right)^{-1} W^{\prime}$, see Härdle and Linton (1994) for a discussion on the properties of this procedure.

When working with macroecomic variables, the sample sizes are usually too small to obtain consistent and efficient nonparametric or semiparametric estimators. However, as we will see in the empirical application of the UK money demand, this semiparametric procedure can be very informative in finding appropriate types of nonlinear functional forms, cubic polynomials, rational polynomials, etc. The final empirical step should therefore consist of the estimation of NEC models from those suggested parametric specifications. This final step should provide more efficient estimates.

\subsection{Parametric Approach}

Assumption 2. The vector $\left(\Delta y_{t}, \Delta q_{t}^{\prime}\right)^{\prime}$ satisfies a FCLT based on NED sequences, and $z_{t}$ satisfies Assumption 1.

THEOREM 3 (TWO-STEP ESTIMATOR OF NEC). Under Assumption 2 and conditions $(i)-(v)$ of Theorem 1 ,

$$
\begin{gathered}
y_{t}=\alpha^{\prime} q_{t}+z_{t} \\
\Delta y_{t}=b_{0}^{\prime} \Delta q_{t}+b_{1}^{\prime} \Delta q_{t-1}+\cdots+b_{r}^{\prime} \Delta q_{t-r}+a_{1} \Delta y_{t-1}+\cdots \\
+a_{p} \Delta y_{t-p}+f\left(z_{t-1}, \gamma\right)+\varepsilon_{y t} .
\end{gathered}
$$

Equations (17a) and (17b) can be estimated by OLS and NLS with the following properties:

(a) The OLS estimator of the cointegrating vector $\boldsymbol{\alpha}$, in (17a), is superconsistent and its asymptotic distribution is nonstandard.

(b) The OLS and NLS estimators of the parameters $\left(b_{0}, b_{1}, \ldots, b_{r}\right)^{\prime}$ and $\left(a_{1}, \ldots, a_{p}, \gamma\right)$ of equation (17b) have the same limiting distribution no matter what value of $z_{t-1}$ we use: the true value $\left(z_{t-1}\right)$ or its OLS estimate, $\left(U_{t-1}\right)$, from $(17 a)$.

(c) The OLS or NLS estimators of the parameters $\left(b_{0}, b_{1}, \ldots, b_{r}\right)^{\prime}$ and $\left(a_{1}, \ldots, a_{p}, \gamma\right)$ of equation $(17 b)$, where $z_{t-1}$ was previously estimated $\left(U_{t-1}\right)$ by OLS on $(17 a)$, are $\sqrt{ } T$-consistent and asymptotically normal.

Proof. See Appendix A.

Those least-squares (LS) estimation results are based on Stock (1987) and Escribano and Mira (1996, 1997) and generalize Engle and Granger (1987) twostep estimator to single-equation NEC models. 
Most of the previous results on estimation and inference in NEC models are based on parametric procedures (OLS, NLS) when the nonlinear functional form is known. However, the functional form is generally unknown and, if we start with the wrong class of nonlinear functions, it might be difficult to reach a good model. As will become clear in the next section, to overcome this problem we suggest starting the nonlinear specification with the semiparametric estimation procedure mentioned in Section 3.1 in order to find out plausible parametric functional forms for the nonlinear equilibrium correction. However, this makes sense if we have previously identified certain nonlinearities in the model. This procedure is explained in the next section.

\subsection{Testing for the Existence of NEC Adjustments}

The first step of the methodology is the estimation of a linear specification. Once we have evidence of cointegration and have specified a linear EC model, usual misspecification tests can be applied to test for nonlinearities in the equilibrium correction. For example, one can use an LM test based on the $R^{2}$ of auxiliary regressions (using the asymptotic $\chi^{2}$ distribution) or its small-sample counterpart (based on the $F$ distribution) to test the null hypothesis of linear error correction $\left(H_{0}:\right.$ EC) against the alternative hypothesis of nonlinear error correction $\left(H_{1}\right.$ : NEC). Alternatively, we could use the likelihood ratio (LR) or Wald (W) tests. Sometimes, LM tests have the advantage of being easier to compute in nonlinear cases. Furthermore LM tests can be used to identify certain types of parametric functional forms to be used. For example, when selecting between logistic and exponential specifications, Teräsvirta (1994) proposed an interesting decision rule, in the context of smooth-transition autoregression models (STAR). Escribano and Jorda $(1999,2001)$ suggested an alternative decision rule and extended the analysis to the class of smooth-transition regression models (STR). As we will see later, those decision rules based on LM tests could also be informative when deciding among alternative nonlinear functional forms in NEC models.

If the linear error-correction model have been rejected in favor of a nonlinear error correction, then we should follow a semiparametric estimation procedure (smoothing splines, kernels, etc.) to identify the class of parametric nonlinear functions. This strategy is most relevant in the absence of large sample sizes since parametric estimates will be more efficient and the corresponding test statistics more powerful.

Once we have estimated a plausible parametric nonlinear formulation of the error correction adjustment (NEC), the usual misspecification tests should be applied to test the null hypothesis of correct specification against the alternative misspecification hypotheses: autocorrelation, heteroskedasticity, wrong dynamic specification, parameter nonconstancy, etc.

In the following sections we apply this econometric methodology to different periods of the UK money demand and discuss competing estimates, some of which were mentioned critically by Friedman and Schwartz (1991). 


\section{EMPIRICAL APPLICATIONS OF NEC METHODOLOGY}

We start this section with a brief historical review of some of the first unpublished competing UK money demand estimates based on annual observations from the year 1878 to 1970 . The database was originally obtained from Friedman and Schwartz (1982) but rescaled as in Hendry and Ericsson (1983) to compensate for the Southern Ireland effect. Table 1 includes the three main unpublished competing specifications of the money demand that were independently proposed. One of them represents the first nonlinear and asymmetric error-correction model estimated. In what follows, we briefly highlight the basic differential elements of the three alternative money demand specifications.

Hendry and Ericsson (1983) estimated an EC money demand equation in onestep (see Table 1, col. 2) by OLS, as a critical reaction to the empirical approach followed by Friedman and Schwartz (1982). The implicit cointegration relationship was between the log-inverse velocity of circulation of money $(m-p-i)_{t-4}$ and short-run interest rate $(R S)_{t}$. To obtain parameter constancy, their specification needed a questionable dummy variable D2 (see Appendix B), which captures what Friedman and Schwartz (1982) called a "liquidity preference shift." Based on this, Hendry and Ericsson (1983) realized that their specification was not satisfactory. This comment motivated other researchers to look for alternative money demand specifications.

Simultaneously, two different money demand equations were estimated, one at the London Business School in the United Kingdom, by Longbottom and Holly (1985), and the other at the University of California at San Diego (USA) by Escribano (1985, 1986).

Longbottom and Holly (1985) estimated a linear error correction in one-step by OLS (see Table 1, col. 3). The implicit cointegration relationship they considered was among real money stock $(m-p)_{t-1}$, real income $(i)_{t}$, and short-run interest rates in logs $(r s)_{t}$. Therefore, they did not impose a unit income elasticity of real money demand in the long-run. In particular, they suggested the following changes: (i) relax the restriction on the coefficient of the first lagged dependent variable, (ii) use interest rates in logs in both the long run $(r l)$ and the short run $(r s)$, (iii) relax the restriction on the coefficients of the rate of growth of prices, and (iv) impose the same coefficient on both world war dummies, D1 and D3. With those changes, they did not use the dummy variable D2 and reduced the estimated standard error of the regression from $1.7 \%$ to $1.4 \%$.

Escribano (1985, 1986), followed an alternative strategy, estimating a $N E C$ in two-steps (see of Table 1, cols. 3 and 4). The explicit nonlinear cointegration relationship was between log-inverse velocity of circulation of money $(m-p-i)_{t}$ and short-run interest rates $(R S)_{t}$ without logs. The dynamic formulation considered in the second step incorporated the following changes: (i) relax the restrictions on the coefficient of the first lagged dependent variable, (ii) relax the restriction on the coefficients of the growth rate of prices, (iii) include the first difference of both short-run and long-run interest rates ( $R S$ and $R L$ ), and (iv) incorporate the lagged 
TABLE 1. Historical competing estimates of money demand in the UK (1878-1970)

\begin{tabular}{|c|c|c|c|c|}
\hline \multirow[b]{2}{*}{ Regressors } & \multicolumn{4}{|c|}{ Dependent variable } \\
\hline & $\Delta(m-p)_{t}^{a}$ & $\Delta(m-p)_{t}^{b}$ & $(m-p-i)_{t}^{c}$ & $\Delta(m-p)_{t}{ }^{d}$ \\
\hline$\Delta^{2}(m-p)_{t-1}$ & $0.37(7.4)^{e}$ & & & \\
\hline$\Delta^{2}(m-p)_{t-2}$ & $-0.06(0.8)$ & $-0.13(3.1)$ & & \\
\hline$\Delta(m-p)_{t-1}$ & & $0.47(7.5)$ & & $0.45(6.1)$ \\
\hline$\Delta(m-p)_{t-2}$ & & & & $-0.16(3.0)$ \\
\hline$\Delta(m-p)_{t-3}$ & & & & $0.08(1.7)$ \\
\hline$(1 / 4) \Delta_{4} i_{t}$ & $0.64(4.3)$ & & & \\
\hline$\Delta i_{t}$ & & & & $0.08(1.7)$ \\
\hline$\Delta^{2} p_{t}$ & $-0.47(11.7)$ & $-0.63(15.4)$ & & \\
\hline$\Delta^{2} p_{t-2}$ & $-0.14(2.0)$ & & & \\
\hline$\Delta p_{t}$ & & & & $-0.61(13.8)$ \\
\hline$\Delta p_{t-1}$ & & $-0.22(4.8)$ & & $0.37(7.0)$ \\
\hline$\Delta R L_{t}$ & & & & $-0.01(1.8)$ \\
\hline$(1 / 2) \Delta_{2} R L_{t}$ & $-3.3(3.0)$ & & & \\
\hline$\Delta_{2} r l_{t}$ & & $-0.0108(5.9)$ & & \\
\hline$\Delta R S_{t}$ & & & & $-0.008(3.7)$ \\
\hline$(m-p-i)_{t-4}$ & $-0.20(10.0)$ & & & \\
\hline$(m-p)_{t-1}$ & & $-0.058(4.0)$ & & \\
\hline$i_{t}$ & & $0.065(4.4)$ & & \\
\hline$R S_{t}$ & $-0.78(4.3)$ & & -0.7 & \\
\hline$r s_{t}$ & & $-0.0056(1.6)$ & & \\
\hline$D 1$ & $1.9(2.4)$ & & & $0.04(4.4)$ \\
\hline$D 2$ & $3.6(6.0)$ & & & \\
\hline D3 & $0.6(0.7)$ & & & $0.04(6.1)$ \\
\hline$D 1+D 3$ & & $0.034(6.2)$ & & \\
\hline$U_{t-1}^{f}$ & & & & $-0.018(0.6)$ \\
\hline$U_{t-1}^{2}$ & & & & $0.5(3.3)$ \\
\hline$U_{t-1}^{t-1}$ & & & & $-2.18(2.3)$ \\
\hline Constant & $-0.086(0.7)$ & $-0.074(2.4)$ & -4.91 & $0.004(1.6)$ \\
\hline$R^{2}$ & 0.82 & 0.86 & 0.56 & 0.87 \\
\hline $100 \sigma$ & $1.7 \%$ & $1.46 \%$ & $10.9 \%$ & $1.46 \%$ \\
\hline No. of parameters & 12 & 10 & 2 & 14 \\
\hline
\end{tabular}

${ }^{a}$ Hendry and Ericsson (1983) one-step EC.

${ }^{b}$ Longbottom and Holly (1985) one-step EC.

${ }^{c}$ Escribano $(1985,1986)$ cointegration.

${ }^{d}$ Escribano $(1985,1986)$ two-step NEC.

${ }^{e}$ Absolute values of $t$ ratios are in parentheses.

${ }^{f} U_{t-1}=(m-i-p)_{t-1}+4.91+0.7 R S_{t-1}$. 
residuals $\left(U_{t-1}\right)$ from the cointegrating relationship in a nonlinear form (cubic polynomial error correction). The incorporation of the nonlinear equilibrium correction made the contribution of the dummy variable D2 insignificant and reduced the estimated standard regression error of the regression from $1.7 \%$ to $1.4 \%$. Both alternative parameterizations-columns 3 and 5 of Table 1 -represented significant improvements over previous money demand equations, as was later recognized by Friedman and Schwartz (1991) and Hendry and Ericsson (1991).

\subsection{Empirical Application of NEC Methodology to the UK Money Demand from 1878 to 1970}

This section is based on the seminal work of Escribano $(1985,1986,1996)$ and therefore uses the original data set to describe the econometric methodology discussed in Sections 2 and 3 when searching for nonparametric and parametric functional NEC models. For the stability analysis, larger data sets will be considered. The usual first step in dynamic single-equation modeling is to analyze the univariate time-series properties of the variables. This is important to determine the class of models and the estimation and inference properties that we should consider. However, since the descriptive analysis of this data set can be found in Friedman and Schwartz (1982) and in Hendry and Ericsson (1991), we only discuss what is different in terms of the $I(1)$ and $I(0)$ properties of the variables.

Recall from Theorem 1 that the vector $\boldsymbol{X}_{t}=\left(y_{t}, q_{t}^{\prime}\right)^{\prime}$, where $y_{t}$ is a scalar and $q_{t}$ is an $(N-1) \times 1$ vector. The dependent variable that we want to explain in the dynamic regression analysis is the log of the real money stock $y_{t} \equiv(m-p)_{t}$ and its rate of growth $\Delta y_{t} \equiv \Delta(m-p)_{t}$. The set of explanatory variables form an $8 \times 1$ vector $\left(q_{t}\right)^{\prime} \equiv(i, p, r s, r l, D 1, D 2, D 3,1)_{t}^{\prime}$ where the first component $(i)$ is the log of real income, $(p)$ is the implicit price deflator of real income in logs, $(r s)$ is the log of the short-run interest rate, $(r l)$ is the long-run interest in logs, and the variables $(D 1),(D 3)$, and (D2) are dummy variables to capture special events such as World War I, World War II, and a "liquidity preference shift," produced by "economic depression and war," following the work of Friedman and Schwartz (1982, p. 281). The precise definitions of the variables are given in Appendix B.

When the true model is a NEC model, we might first want to check that the twostep estimation procedure works correctly, giving consistent OLS estimates of the cointegration relationship in the presence of a nonlinear model of the residuals. Theorem 3 requires that the errors from the cointegrating relationship are $\alpha$-mixing, satisfy Assumption 1, and the first difference of the variables of the model is $I(0)$ and satisfies Assumption 1. All of these conditions are testable.

In Table 2, we report the numerical values of Lo (1991) and Kwiatkowski et al. (1992) test statistics obtained for the following components of the vector of first differences $\left.(\Delta(m-p), \Delta i, \Delta p, \Delta r s, \Delta r l, \Delta R L)_{t}^{\prime}\right)^{\prime}$.

Given that all estimated values of the test statistics are inside the $95 \%$ confidence interval, we cannot reject the null hypotheses that the variables in first differences are $I(0)$ and satisfy Assumption 1 against the alternative hypothesis of $I(1)$. If we 
TABle 2. $H_{0}: x_{t}$ is $I(0)$ and satisfies Assumption $1 ; H_{1}: x_{t}$ is $I(1)$ and/or does not satisfy Assumption 1

\begin{tabular}{lcccccccc}
\hline Test statistic $^{a}$ & $\Delta(m-p)$ & $\Delta i$ & $\Delta p$ & $\Delta r s$ & $\Delta r l$ & $\Delta R L$ & $u$ & $U$ \\
\hline Lo (1991) & 1.23 & 1.05 & 0.98 & 0.86 & 1.27 & 1.38 & 1.20 & 1.30 \\
Kwiatkowski et al. (1992) & 0.22 & 0.07 & 0.37 & 0.12 & 0.37 & 0.55 & 0.13 & 0.24 \\
\hline
\end{tabular}

${ }^{a}$ Lo's $95 \%$ asymptotic confidence interval, $\mathrm{CI}=(0.86,1.75)$. KPSS's $95 \%$ asymptotic confidence interval, $\mathrm{CI}=(0$, $0.46)$. In both test statistics, the truncation lag used to estimate the variance of $x_{t}$ was always the optimal; $s=$ integer value of $K_{T}$. See equations (6a), (6b), and (7) of Section 3.

plot the first difference of the relevant series from 1878-2000, it is clear that none of the series in first differences look like $I(1)$, confirming the results of the test statistics that the first difference of the variables is $I(0)$ and therefore the partial sums are $I(1)$.

Furthermore, from unit root tests and the evolution of the autocorrelations and partial autocorrelation of the univariate time series, we conclude that the components of the vector $\boldsymbol{X}_{t}=\left(y_{t}, q_{t}^{\prime}\right)^{\prime}$, except for the dummy variables and the constant, can be characterized as $I(1)$; see Escribano (1985, 1986), Hendry and Ericsson (1991) and Ericsson et al. (1998) for more details.

In the last two columns of Table 2, we report several cointegrating tests, under the assumption that $R S_{t}$ (or $r s_{t}$ ) are strictly exogenous in their corresponding cointegrating regression. The results of testing the null hypothesis $\left(H_{0}\right)$ of cointegration are based on the test statistic of $\mathrm{KPSS}_{T}$ extended by Shin (1994). From the results of column 8 of Table 2, we cannot reject that there is a cointegrating relationship $\left(H_{0}\right)$ between inverse velocity of circulation of money in logs, $(m-i-p)_{t}$, and short-run interest rates in logs, $(r n)_{t}$. Similarly, column 9 of Table 2 shows that there is no evidence against a nonlinear cointegrating relationship $\left(H_{0}\right)$ between inverse velocity of circulation of money in $\operatorname{logs},(m-i-p)_{t}$ and short-run interest rates without $\operatorname{logs},(R N)_{t}$. In both cases the test statistics based on the residuals, $u$ and $U$ from the OLS-cointegrating regressions, are inside the $95 \%$ confidence interval. Therefore, in both cases, we cannot reject the null hypothesis of cointegration against the alternative hypothesis that the residuals are $I(1)$ and/or do not satisfy Assumption 1. The power of the test and the small-sample critical value (C.V.) require a deeper analysis but the study is beyond the scope of this paper.

Given that the variables are cointegrated, we can proceed by estimating a linear error correction model; see Table 3. Following the results of Escribano (1985, 1986), Table 3 confirms the previous evidence against the null hypothesis of no cointegration $\left[U_{t}\right.$ is $\left.I(1)\right]$ between log-inverse velocity of circulation of money $(m-i-p)_{t}$ and short-run interest rates $(R S)_{t}$, with a $t$-ratio of $U_{t-1}$ equal to -3.2.

Once we have found a plausible linear error-correction model, we could test for the existence of an NEC model. We could do that by using standard testing principles based on Lagrange multipliers (LM), Wald (W), or likelihood ratio (LR). As 
TABLE 3. Linear EC money demand in the UK (1878-1970)

\begin{tabular}{|c|c|c|c|c|}
\hline \multirow[b]{2}{*}{ Regressors } & \multicolumn{4}{|c|}{ Dependent Variable: $\Delta(m-p)_{t}$} \\
\hline & Coefficient & Std. Error & T-Statistic & Prob. \\
\hline$\Delta(m-p)_{t-1}$ & 0.47 & 0.06 & 7.36 & 0.0000 \\
\hline$\Delta^{2}(m-p)_{t-2}$ & -0.11 & 0.04 & -2.68 & 0.0086 \\
\hline$\Delta p_{t}$ & -0.60 & 0.04 & -14.20 & 0.0000 \\
\hline$\Delta p_{t-1}$ & 0.41 & 0.04 & 8.43 & 0.0000 \\
\hline$\Delta r s_{t}$ & -0.01 & 0.005 & -3.13 & 0.0023 \\
\hline$\Delta_{2} r l_{t}$ & -0.07 & 0.01 & -4.18 & 0.0001 \\
\hline$D 1+D 3$ & 0.03 & 0.005 & 5.76 & 0.0000 \\
\hline$U_{t-1}$ & -0.04 & 0.01 & -3.12 & 0.0024 \\
\hline Constant & 0.009 & 0.002 & 4.49 & 0.0000 \\
\hline$R^{2}$ & 0.85 & & & \\
\hline Adjusted $R^{2}$ & 0.84 & & & \\
\hline$\sigma$ & 1.5 & & & \\
\hline Sum-squared residual & 0.019 & & & \\
\hline Durbin-Watson statistic & 1.83 & & & \\
\hline Mean dependent variable & 0.014 & & & \\
\hline S.D. dependent variable & 0.037 & & & \\
\hline Akaike info criterion & -8.29 & & & \\
\hline Schwartz criterion & -8.04 & & & \\
\hline \multicolumn{5}{|c|}{$\begin{array}{c}\text { Nonlinear Error Correction Test } \\
\mathrm{H}_{0}: \text { Linear EC } \\
\mathrm{H}_{1}: \text { Nonlinear EC }(\mathrm{NEC})\end{array}$} \\
\hline \multicolumn{5}{|c|}{ Omitted variables test: $U_{t-1}^{2}, U_{t-1}^{3}$} \\
\hline$F$-statistic & 5.3345 & Probability & $0.0066^{a}$ & \\
\hline Log likelihood & 11.3754 & Probability & $0.0033^{a}$ & \\
\hline
\end{tabular}

${ }^{a}$ Significant rejection of linearity at $1 \%$.

we mentioned earlier the LM test is probably the simplest test against nonlinear alternatives since all we have to do is estimate an artificial regression using the residuals from the linear error-correction model as the dependent variable and the explanatory variables of the linear EC model as the regressors, plus polynomial terms of the first lag of the residuals from the OLS cointegrating relationship estimated in the first step, $U_{t-1}^{2}$ and $U_{t-1}^{3}$. However, if the NEC model can also be estimated by OLS, this advantage of the LM test disappears. For example, in Table 3, we report the results of implementing an LR test for the null hypothesis of linearity against the alternative of NEC. The log likelihood, or its small-sample counterpart $F$-statistic, has $p$-values smaller than 0.05 , rejecting the null of linearity in favor of NEC. As discussed by Teräsvirta (1994) and Escribano and Jorda (1999, 2001), the LM tests for linearity, based on the alternative hypothesis of cubic polynomials or fourth-order polynomials, have power against logistic or 
exponential nonlinear models. However, for reasons that will be mentioned later, we suggest considering a new class of nonlinear functions: rational polynomial error-correction models.

Once we have found evidence of a NEC model, we suggest estimating the unknown nonlinear relationship by the semiparametric procedure based on smoothing splines; see Section 2.

Given that we have rejected the null hypothesis of linear error correction in favor of NEC, we could maintain the parametric linear dynamic specification while allowing the nonlinearity to affect only the error correction term. Applying the smoothing-splines estimation procedure to the money demand of the United Kingdom (1878-1970), we find that the number of intervals $K$ is 11 and that the estimated (optimal) value of the smoothing parameter $\lambda$ is $\lambda=0.00001216$. The empirical results obtained are reported in Model A of Table 4.

The graphical representation of the nonlinear adjustment is in Figure 1. From the graph it is again clear that the two attractor points (equilibria) are 0 and 0.2. We could also interpret the values of $U$ between 0 and 0.2 representing the multiple long-run equilibria of the money demand. It is interesting to realize that the nonlinear plot of this semiparametric estimation looks like the cubic polynomial plot previously obtained.

TABLE 4. Smoothing splines estimation of nonlinear equilibrium corrections

\begin{tabular}{|c|c|c|c|c|c|}
\hline \multicolumn{3}{|c|}{ Model 4A } & \multicolumn{3}{|c|}{ Model 4B } \\
\hline Intervals & Coefficients & $t$-Ratios & Intervals & Coefficients & $t$-Ratios \\
\hline 1 & 0.0301 & 5.28 & 1 & 0.0121 & 3.99 \\
\hline 2 & 0.0127 & 4.76 & 2 & 0.0093 & 3.95 \\
\hline 3 & 0.0074 & 3.28 & 3 & 0.0082 & 3.86 \\
\hline 4 & 0.0051 & 2.30 & 4 & 0.0076 & 3.79 \\
\hline 5 & -0.00084 & -0.37 & 5 & 0.0060 & 3.38 \\
\hline 6 & -0.00241 & -1.03 & 6 & 0.0048 & 2.90 \\
\hline 7 & -0.00011 & -0.04 & 7 & 0.0032 & 1.92 \\
\hline 8 & 0.00386 & 1.13 & 8 & 0.0009 & 0.49 \\
\hline 9 & 0.00029 & 0.08 & 9 & -0.0024 & -0.97 \\
\hline 10 & 0.00068 & 0.16 & 10 & -0.0058 & -1.17 \\
\hline 11 & -0.00574 & -1.04 & 11 & -0.0081 & -2.01 \\
\hline \multicolumn{3}{|c|}{ Sample period: $1878-1970$} & \multicolumn{3}{|c|}{ Sample period: $1878-1970$} \\
\hline \multicolumn{3}{|c|}{ No. of observations: 93} & \multicolumn{3}{|c|}{ No. of observations: 93} \\
\hline \multicolumn{3}{|c|}{ Standard error of the regression: $1.51 \%$} & \multicolumn{3}{|c|}{ Standard error of the regression: $1.67 \%$} \\
\hline \multicolumn{3}{|c|}{ Standard error with denominator trace: $1.45 \%$} & \multicolumn{3}{|c|}{$\begin{array}{l}\text { Standard error with denominator } \\
\text { trace: } 1.58\end{array}$} \\
\hline \multicolumn{3}{|c|}{ Optimal value of $\lambda: 0.00001216$} & \multicolumn{3}{|c|}{ Value of $\lambda: 10,000$} \\
\hline \multicolumn{3}{|c|}{ GCV: 0.0000024} & \multicolumn{3}{|c|}{ GCV: 0.0000027} \\
\hline \multicolumn{3}{|c|}{ Durbin-Watson: 2.02} & \multicolumn{3}{|c|}{ Durbin-Watson: 2.00} \\
\hline
\end{tabular}


Model A of Table 4: Smoothing splines with optimal value of $\lambda=\mathbf{0 . 0 0 0 0 1 2 1 6}$

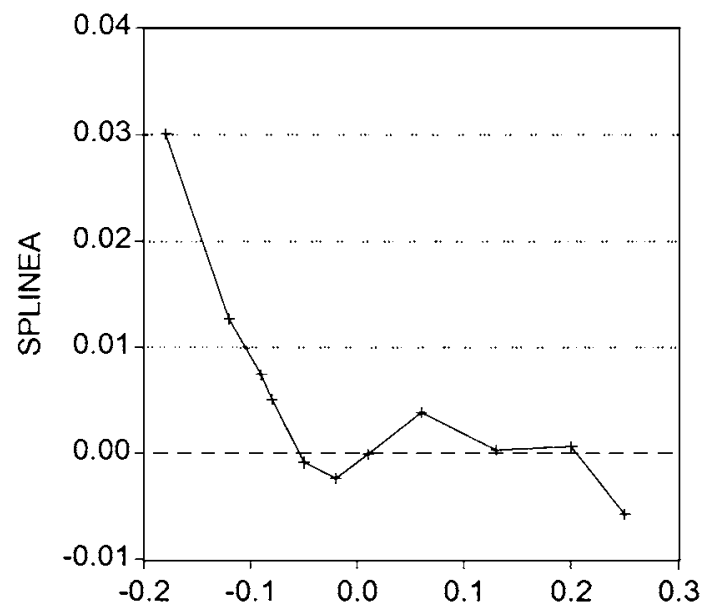

EC

Model B of Table 4: Smoothing splines fixing the value of $\lambda=10,000$

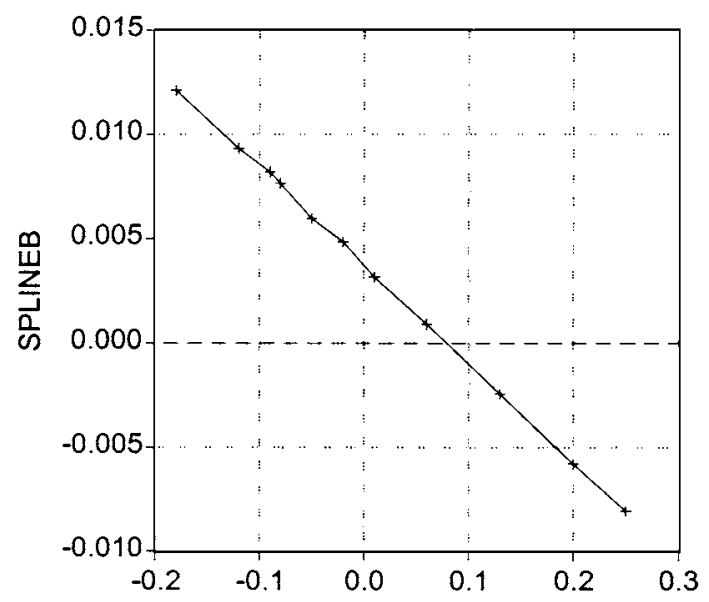

EC

FigURE 1. Nonparametric Error Correction (Smoothing Splines) UK Money Demand (18781970). 
Therefore, the nonparametric estimation supports cubic polynomials as plausible parametric functional approximations of the nonlinear equilibrium correction. The next closest parametric alternative is the rational polynomial, which as we mentioned before, has an important advantage over cubic polynomials, since it is consistent with $U_{t}$ being $\phi$-NED.

One possible interpretation of the asymmetric adjustment is that it is piecewise nonlinear only with negative equilibrium errors but the adjustment is linear with positive errors greater than or equal to 0.2 . The economic and statistical interpretation of this possibility is unclear but it could be justified by having certain asymmetric adjustment costs.

When imposing a strong smoothing constraint (large value of the smoothing parameter $\lambda$ ) on the splines estimator, we get a linear error-correction adjustment. This linear error-correction model was obtained by setting the value of $\lambda$ at 10,000 while keeping 11 intervals; see Model 4B of Table 4. The graphical representation of the linear error-correction adjustment is in Figure 1. From the graph, it is clear that the whole adjustment is biased toward the value of $U=0.2$, thus explaining why the initial estimates of the UK money demand (1878-1970) required the use of the dummy variable $D 2$ in their linear specifications.

The final money demand of Hendry and Ericsson (1991) is a NEC model estimated by the two-step procedure of Engle and Granger (1987); see columns 2 and 3 of Table 3. Following Escribano $(1985,1986)$, they incorporated the residuals from the OLS estimator $\left(U_{t}\right)$, lagged once, as a cubic polynomial in the dynamic formulation. The NEC term of Hendry and Ericsson (1991) is in column 3 of Table 5, $-2.55\left(U_{t-1}-0.2\right) U_{t-1}^{2}=0.5 U_{t-1}^{2}-2.55 U_{t-1}^{3}$. Following Longbottom and Holly (1985), they also included the short run and the long-run interest rates in logs (rates of change) in the short run. In the last rows of column 3 of Table 5, we present several misspecification tests. We were unable to reject the null hypothesis of correct specification. That is, or $\mathrm{AR}(2)$ structure in the residuals, or $\mathrm{ARCH}(1)$, etc.

Following Granger and Lee (1989) in the last column of Table 5, we report the estimation of an asymmetric error-correction model with the threshold point $(\tau)$ at 0 . However, this model is worse since the standard error of the regression increases from $1.42 \%$ to $1.46 \%$ and only the negative errors are significantly different from zero. In Section 5, we will give an explanation of this result using the extended data set going from 1878 to 2000 .

\subsection{Econometric Evaluation of Ericsson et al. (1998) UK Money Demand Estimates}

Hendry and Ericsson (1991) also extended the model presented in column 3 of Table 5 to cover the period from 1970 to 1975 . This is an important period due to the introduction of Competition and Credit Control regulations. To account for that, they define a dummy variable $D 4$, see Appendix B, which also enters interactively with the rate of growth of the short-run $(\Delta r s)$ interest rates, $(D 4 \Delta r s)$. Additional data from 1975 to 1993 were compiled by Attfield et al. (1995) and examined by 
TABLE 5. Money demand in the UK estimates from 1878-1970

\begin{tabular}{|c|c|c|c|c|}
\hline \multirow[b]{2}{*}{ Regressors } & \multicolumn{4}{|c|}{ Dependent variable } \\
\hline & $(m-i-p)_{t}^{a}$ & $\Delta(m-p)_{t}^{b}$ & $\Delta(m-p)_{t}^{c}$ & $\Delta(m-p)_{t}{ }^{d}$ \\
\hline$\Delta^{2}(m-p)_{t-2}$ & & $-0.10(2.5)^{e}$ & $-0.10(2.4)$ & $-0.09(2.0)$ \\
\hline$\Delta(m-p)_{t-1}$ & & $0.45(7.4)$ & $0.45(7.1)$ & $0.43(6.6)$ \\
\hline$\Delta p_{t}$ & & $-0.60(15.0)$ & $-0.59(14.8)$ & $-0.59(14.4)$ \\
\hline$\Delta p_{t-1}$ & & $0.39(8.5)$ & $0.39(8.4)$ & $0.38(8.0)$ \\
\hline$\Delta_{2} r l_{t}$ & & $-0.062(3.4)$ & $-0.062(3.4)$ & $-0.065(3.4)$ \\
\hline$\Delta r s_{t}$ & & $-0.021(3.9)$ & $-0.021(3.9)$ & $-0.021(3.7)$ \\
\hline$R S_{t}$ & -7.0 & & & \\
\hline$D 1+D 3$ & & $3.7(6.8)$ & $3.7(6.6)$ & $3.8(6.5)$ \\
\hline$U_{t-1}^{f}$ & & & & \\
\hline$U_{t-1}^{2}$ & & & $0.50(3.4)$ & \\
\hline$U_{t-1}^{3}$ & & & $-2.55(4.6)$ & \\
\hline$\left(U_{t-1}-0.2\right) U_{t-1}^{2}$ & & $-2.55(4.6)$ & & \\
\hline$U_{t-1} D\left(U_{t-1}>0\right)$ & & & & $0.01(0.5)$ \\
\hline$U_{t-1} D\left(U_{t-1} \leq 0\right)$ & & & & $-0.15(3.6)$ \\
\hline Constant & -0.31 & $0.005(2.4)$ & $0.005(2.2)$ & $0.002(0.7)$ \\
\hline$T$ & $98(1873-1970)$ & 93 & 93 & 93 \\
\hline$R^{2}$ & 0.56 & 0.87 & 0.87 & 0.86 \\
\hline $100 \sigma$ & $10.9 \%$ & $1.42 \%$ & $1.43 \%$ & $1.46 \%$ \\
\hline No. of parameters & 2 & 9 & 10 & 10 \\
\hline Misspecification test & & $p$-value & $p$-value & $p$-value \\
\hline $\mathrm{AR}(2)$ & & 0.26 & 0.26 & 0.16 \\
\hline $\mathrm{ARCH}(1)$ & & 0.22 & 0.23 & 0.41 \\
\hline Normality & & 0.38 & 0.37 & 0.35 \\
\hline$X_{i}^{2}$ & & 0.60 & 0.71 & 0.24 \\
\hline$X_{i} * X_{j}$ & & 0.76 & 0.88 & 0.24 \\
\hline RESET & & 0.52 & 0.52 & 0.98 \\
\hline
\end{tabular}

${ }^{a}$ Hendry and Ericsson (1991) cointegration.

${ }^{b}$ Hendry and Ericsson (1991) two-step NEC.

${ }^{c}$ Cubic polynomial two-step NEC.

${ }^{d}$ Asymmetric two-step NEC.

${ }^{e}$ Absolute values of $t$-ratios are in parentheses.

${ }^{f} U_{t-1}=(m-p-i)_{t-1}+0.31+7.0 R S_{t-1}$.

Ericsson et al. (1998). We replicate their two-step estimation in column 2 of Table 6. In step 1, they estimate the long-run parameters from the cointegrating relationship using the period of 1873-1970 and impose those estimated parameter values of the cointegrating vector for the period 1873-1993. In step 2, they estimate the error-correction model including cubic polynomial equilibrium correction terms, following Escribano (1985, 1986). However, as we can see in the misspecification test included in the last rows of Table 6 , col. 2 , there is clear evidence of some autocorrelation, $\operatorname{AR}(2)$, in the residuals of the model. 
TABLE 6. Money demand in the UK estimates from 1878 to 1993 (dependent variable: rate of change of real stock of money)

\begin{tabular}{lccrr}
\hline & \multicolumn{4}{c}{ Dependent variable } \\
\cline { 2 - 5 } Regressors & $\Delta(m-p)_{t}{ }^{a}$ & $\Delta(m-p)_{t}{ }^{b}$ & $\Delta(m-p)_{t}{ }^{c}$ & $\Delta(m-p)_{t}{ }^{d}$ \\
\hline$\Delta^{2}(m-p)_{t-2}$ & $-0.10(2.35)^{e}$ & $-0.10(2.33)$ & $-0.10(3.10)$ & $-0.08(1.72)$ \\
$\Delta(m-p)_{t-1}$ & $0.48(9.00)$ & $0.49(8.83)$ & $0.66(8.93)$ & $0.64(8.45)$ \\
$\Delta(m-p)_{t-2}$ & & & $-0.21(3.32)$ & $-0.20(3.13)$ \\
$\Delta p_{t}$ & $-0.62(14.89)$ & $-0.62(14.59)$ & $-0.64(15.77)$ & $-0.62(14.86)$ \\
$\Delta p_{t-1}$ & $0.40(8.77)$ & $0.41(8.90)$ & $0.57(7.61)$ & $0.52(6.92)$ \\
$\Delta p_{t-2}$ & & & $-0.15(2.62)$ & $-0.10(1.70)$ \\
$\Delta_{2} r l_{t}$ & $-0.04(2.55)$ & $-0.04(2.50)$ & $-0.04(2.50)$ & $-0.04(2.36)$ \\
$\Delta r n_{t}^{a}$ & $-0.02(3.39)$ & $-0.02(3.34)$ & $-0.02(3.65)$ & $-0.02(3.69)$ \\
$D c$ & $0.05(7.27)$ & $0.05(7.24)$ & $0.05(7.00)$ & $0.05(7.15)$ \\
$D 1+D 3$ & $0.0039(7.11)$ & $0.04(6.52)$ & $0.04(6.56)$ & $0.03(6.36)$ \\
$D 4 \Delta r s$ & $0.10(3.77)$ & $0.09(3.24)$ & $0.08(3.14)$ & $0.07(2.72)$ \\
$\left(U_{t-1}-\alpha\right) U_{t-1}^{2}$ & $-2.26(6.77)$ & $-2.13(4.44)$ & $-2.21(6.08)$ & $-2.00(4.34)$ \\
Parameter $\alpha$ & $0.2($ fixed) & $0.13(1.11)$ & $0.2($ fixed) & $0.18(2.26)$ \\
Constant & $0.004(1.93)$ & $0.01(2.18)$ & $0.01(3.10)$ & $0.01(2.60)$ \\
\hline
\end{tabular}

\begin{tabular}{lcccc}
\hline \multicolumn{5}{c}{ Cointegration relationship : $U_{t}=(m-p-i)_{t}-\alpha_{0}-\alpha_{1} R N_{t}^{a}$} \\
\hline Constant & $-0.32(15.33)$ & $-0.30(6.95)$ & $-0.34(17.28)$ & $-0.30(8.89)$ \\
$R N_{t}^{a}$ & $-6.67(11.67)$ & $-6.89(17.67)$ & $-6.30(13.84)$ & $-7.03(15.73)$ \\
$T$ & 116 & 116 & 116 & 116 \\
$R^{2}$ & 0.87 & 0.87 & 0.88 & 0.89 \\
$100 \sigma$ & $1.62 \%$ & $1.62 \%$ & $1.57 \%$ & $1.56 \%$ \\
No. of parameters & 11 & 14 & 15 & 16 \\
\hline Misspecification tests & $p$-value & $p$-value & $p$-value & $p$-value \\
\hline AR(2) & $0.03^{f}$ & 0.07 & 0.16 & 0.12 \\
ARCH(1) & 0.90 & 0.81 & 0.96 & 0.81 \\
Normality & 0.98 & 0.98 & 0.78 & 0.89 \\
$X_{i}^{2}$ & 0.57 & 0.64 & 0.70 & 0.72 \\
$X_{i} * X_{j}$ & 0.57 & & 0.65 & \\
RESET & 0.25 & & 0.65 & \\
\hline
\end{tabular}

\footnotetext{
${ }^{a}$ Hendry et al. (1998) two-step NEC OLS.

${ }^{b}$ Hendry et al. (1998) one-step NEC NLS.

${ }^{c}$ Two-step NEC OLS.

${ }^{d}$ One-step NEC NLS.

${ }^{e}$ Absolute values of $t$-ratios are in parentheses.

${ }^{f}$ Significant at $5 \%$.
}

This problem is mitigated but not solved by estimating this model in one step by nonlinear least squares (NLS) (see column 3 of Table 6). Columns 4 and 5 of Table 6 show that their specification can be improved by getting rid of the constraint imposed on the lagged dependent variable at lags 2 and 3. To test for 
that, we included the variable $\Delta p_{t-2}$ as an extra regressor. It became significant with an absolute value of the $t$-ratio equal to 2.62, and after that the model passes all the misspecification tests (see last rows of columns 4 and 5 of Table 6). Therefore, from now on we will use the NEC specification obtained in columns 4 and 5 as a benchmark when searching for alternative nonlinear money-demand specifications during the extended period of 1878 to 2000 .

\section{NEC MODELS OF UK MONEY DEMAND FROM 1878 TO 2000}

The first aspect we want to address in this section is the fact that we have a nonlinear cointegration relationship between the log of velocity of circulation of money, $v=-(m-p-i)$, and short-run interest rates without $\operatorname{logs}, R N^{a}=R N A$, Figure $2 \mathrm{~A}$. This implies that there is a long-run money demand relationship between real money in logs $(m-p)_{t}$ and short-run interest $\left(R N^{a}\right)_{t}$ with a constant unit income ( $i$ ) elasticity. A linear cointegrating relationship is obtained if we include $R N^{a}$ in $\operatorname{logs}, r n^{a}=L R N A$, in the cointegrating relationship; see Figure $2 \mathrm{~B}$.

Nonlinear cointegration relationships raise difficult econometric questions:

(i) What do we mean by nonlinear cointegration?

(ii) Can we have a representation theorem for NEC models, similar to Theorem 4 of Escribano and Mira (2002), when the variables are nonlinearly cointegrated?

(iii) Is it possible that two variables are simultaneously linearly and nonlinearly cointegrated?

(iv) If this is the case, which of the two cointegrating relationship is better?

The answer to question (i) was given after Definition 2 of Section 2, using the concepts of integration suggested by Escribano and Mira (1996, 2002).

For general nonlinear cointegrating functions, it is difficult to obtain a representation theorem. However, it is possible to give a simple answer to question (ii) for the particular linear and nonlinear cointegrating functions obtained with the UK money demand since 1878. All we have to do is to consider that in Theorem 2 of Section 2, the vector of explanatory variables $\boldsymbol{q}_{t}$ includes the shortrun interest rates in $\operatorname{logs}\left(r n^{a}\right)$ as well as in levels $\left(R N^{a}\right)$ and that they only enter in the cointegrating vector one at a time. It is an empirical issue which of two cointegrating specifications is the most appropriate. To answer question (iii), we first estimate both cointegrating vectors with very similar long-run results in terms of goodness of fit. The plots of both cointegrating series in Figures $2 \mathrm{~A}$ and $2 \mathrm{~B}$ support the same conclusion. Both pairs of series seem to move together in the long-run but the distance between them varies through time, giving support to the possibility of multiple equilibria and also to the possibility that the adjustment toward the multiple equilibria is not constant. To empirically support those hypotheses, we estimate different NEC models.

First we estimate a NEC model with all of the variables being entered as logs. Therefore, the log variables are linearly cointegrated. The estimation results are given in Model A, col. 2 of Table 7. The NEC model satisfies all the misspecification tests done (see the last rows of column 2 of Table 7). The NEC term is a cubic 

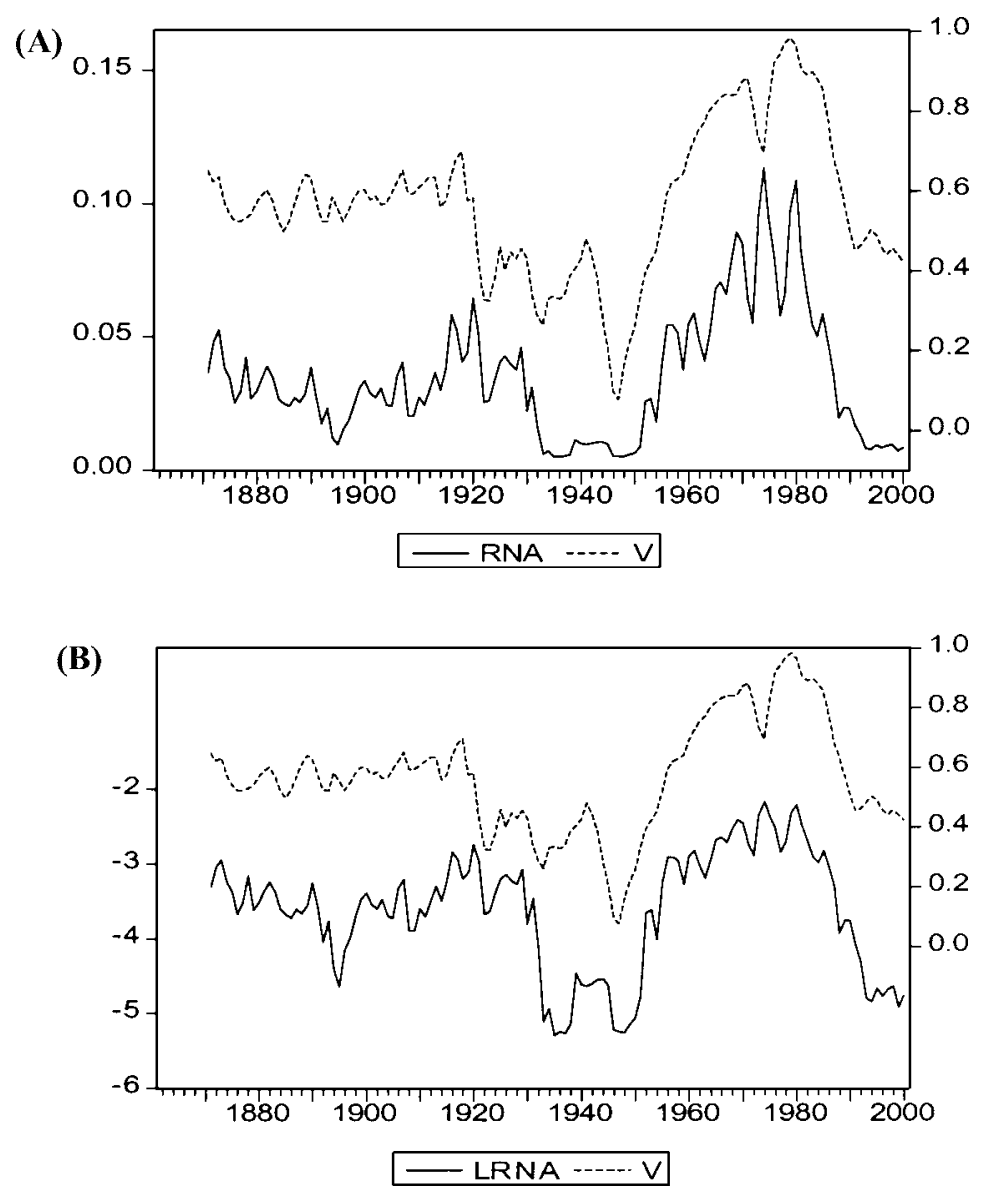

Figure 2. (A) Nonlinear cointegration. (B) Linear cointegration.

polynomial in $u_{t-1}$, where $u_{t}$ is the linear cointegrating error. The corresponding absolute value of the $t$-ratio of $\left(u_{t-1}-0.2\right) u_{t-1}^{2}$ is 4.6 and the standard error of the regression model $\mathrm{A}$ is $1.71 \% .^{3}$

The equivalent analysis is done with the nonlinear cointegrating residuals $U_{t}$. The results are in column 3 of Table 7 , where $U_{t}$ represents the corresponding long-run equilibrium error. Model B of Table 7 shows that the absolute value of the $t$-ratio of the cubic polynomial error-correction term, $\left(U_{t-1}-0.2\right) U_{t-1}^{2}$, is 5.33 and the standard error of the equation is $1.61 \%$. Therefore, in terms of goodness of fit, the answer is clear: The nonlinear cointegration relationship fits better than the linear one.

The cubic polynomial equilibrium correction of Model B, column 3, of Table 7, is plotted in Figure 3. On the horizontal axis, we have the values of the long-run 
TABLE 7. Alternative estimates of money demand in the UK (1878-2000)

\begin{tabular}{|c|c|c|c|c|}
\hline \multirow[b]{2}{*}{ Regressors } & \multicolumn{4}{|c|}{ Dependent variable } \\
\hline & $\Delta(m-p)_{t}^{a}$ & $\Delta(m-p)_{t}^{b}$ & $\Delta(m-p)_{t}{ }^{c}$ & $\Delta(m-p)_{t}{ }^{d}$ \\
\hline$\Delta^{2}(m-p)_{t-2}$ & $-0.10(2.12)^{e}$ & $-0.09(2.15)$ & $-0.09(2.02)$ & $-0.09(5.63)$ \\
\hline$\Delta(m-p)_{t-1}$ & $0.70(8.87)$ & $0.67(8.61)$ & $0.66(8.26)$ & $0.67(8.39)$ \\
\hline$\Delta(m-p)_{t-2}$ & $-0.25(3.83)$ & $-0.24(3.82)$ & $-0.22(3.37)$ & $-0.23(3.49)$ \\
\hline$\Delta p t$ & $-0.68(15.46)$ & $-0.64(15.24)$ & $-0.63(14.55)$ & $-0.64(14.88)$ \\
\hline$\Delta p_{t-1}$ & $0.61(7.65)$ & $0.58(7.57)$ & $0.55(6.94)$ & $0.56(7.16)$ \\
\hline$\Delta p_{t-2}$ & $-0.21(3.34)$ & $-0.15(2.53)$ & $-0.11(1.76)$ & $-0.13(2.03)$ \\
\hline$\Delta_{2} r l_{t}$ & $-0.05(3.10)$ & $-0.04(2.98)$ & $-0.05(3.41)$ & $-0.05(3.30)$ \\
\hline$\Delta_{2} r l_{t-2}$ & & $-0.03(1.95)$ & $-0.04(2.49)$ & $-0.03(2.27)$ \\
\hline$\Delta r n_{t}^{a}$ & $-0.02(3.22)$ & $-0.02(3.61)$ & $-0.02(3.21)$ & $-0.02(3.32)$ \\
\hline$D 1+D 3$ & $0.04(5.99)$ & $0.03(6.29)$ & $0.03(5.44)$ & $0.03(5.63)$ \\
\hline$D 4 \Delta r s$ & $0.11(3.89)$ & $0.08(2.92)$ & $0.07(2.66)$ & $0.08(2.90)$ \\
\hline$D c$ & $0.05(6.25)$ & $0.05(6.68)$ & $0.05(7.15)$ & $0.05(7.02)$ \\
\hline$\left(u_{t-1}-0.2\right) u_{t-1}^{2} f$ & $-2.22(4.60)$ & & & \\
\hline$\left(U_{t-1}-0.2\right) U_{t-1}^{2} g$ & & $-2.02(5.33)$ & & \\
\hline $\begin{array}{l}\left(U_{t-1}^{3}\right) / \\
\quad\left[1 /\left(U_{t-1}+1\right)^{2}+0.21\right]\end{array}$ & & & $-1.66(4.80)$ & \\
\hline$\left(U_{t-1}^{3}\right) /\left[\left(U_{t-1}+1\right)^{2}+1\right]$ & & & & $-3.25(4.67)$ \\
\hline Constant & $0.01(4.14)$ & $0.01(3.83)$ & $0.01(5.69)$ & $0.02(5.63)$ \\
\hline$T$ & 123 & 123 & 123 & 123 \\
\hline$R^{2}$ & 0.85 & 0.87 & 0.86 & 0.87 \\
\hline $100 \sigma$ & $1.71 \%$ & $1.61 \%$ & $1.66 \%$ & $1.64 \%$ \\
\hline No. of parameters & 13 & 14 & 14 & 14 \\
\hline Misspecification tests & $p$-value & $p$-value & $p$-value & $p$-value \\
\hline $\mathrm{AR}(2)$ & 0.46 & 0.15 & 0.31 & 0.30 \\
\hline $\mathrm{ARCH}(1)$ & 0.54 & 0.62 & 0.46 & 0.52 \\
\hline Normality & 0.66 & 0.91 & 0.92 & 0.91 \\
\hline $\begin{array}{l}{ }^{a} \text { Model A, two-step NEC. } \\
{ }^{b} \text { Model B, two-step NEC. } \\
{ }^{c} \text { Model C, two-step NEC. } \\
{ }^{d} \text { Model D, two-step NEC. } \\
{ }^{e} \text { Absolute values of } t \text {-ratios are } \\
{ }^{f} u_{t-1}=(m-i-p)_{t-1}+1.26 \\
{ }^{g} U_{t-1}=(m-i-p)_{t-1}+0.35\end{array}$ & $\begin{array}{l}\text { rentheses. } \\
19 r n_{t-1}^{a} \text {. } \\
16 R N_{t-1}^{a}\end{array}$ & & & \\
\hline
\end{tabular}

equilibrium errors, $U_{t}=(m-p-i)_{t}+0.35+6.16 R N_{t}^{a}$, and on the vertical axis the cubic polynomial error-correction term, $\operatorname{POL}\left(U_{t}\right)=-2.02\left(U_{t}-0.2\right) U_{t}^{2}$ for $t=1878-2000$.

On the other hand, Model A of Table 7 has very similar nonlinear cubic polynomial adjustment (see Figure 4). The horizontal axis has the values of the other long-run equilibrium errors obtained from $u_{t}=(m-p-i)_{t}+1.26+0.19 r n_{t}^{a}$, 
with the short-run interest rates in logs (linear cointegration), and in the vertical axis the cubic polynomial equilibrium correction terms, $\operatorname{POL}\left(u_{t}\right)=-2.22\left(u_{t}-0.2\right) u_{t}^{2}$.

Cubic polynomials are very flexible since they can be thought of as a parametric approximation to any function that is fourth-order continuously differentiable. In fact, for NEC modeling, they represent a very useful tool to identify threshold points. In particular, in the UK money demand since 1878 , we saw that there is a continuum of equilibria between 0 and 0.2 and therefore we can identify two threshold points (attractors) $\tau_{1}=0$ and $\tau_{2}=0.2$ (see Figure 1, Model A and Figure 3). For more than two threshold points, we would need to consider a higher-order polynomial approximation or the nonparametric approach such as the smoothing splines of Section 3.1. Notice that if we specify an asymmetric error correction for the UK money demand with only one threshold point at $\tau=0$ [see Granger and Lee (1989)], it will be misspecified. This is the reason why only adjustments to negative values of $U_{t-1}$ are significant in the Asymmetric NEC Model, column 5, of Table 5. On the contrary, cubic polynomials are robust to having one or two thresholds.

The main caveat of cubic polynomials is that they do not globally satisfy the equilibrium correction condition (stability condition) $-2<d f(z, \gamma) / d z<0$ when $z \rightarrow \infty$, although in sample it could satisfy it. Some other unstable reactions can be observed to the right of the zero equilibrium error; see Figures 3 and 4 . Therefore, we would like to have a class of parametric models that satisfies the previous four desirable properties of cubic polynomials and the stability condition on $d f(z, \gamma) / d z$, which is sufficient for $z_{t}$ to be $\phi$-NED; see Theorem 1. Simple nonlinear functions that satisfy those conditions are certain types of the rational polynomials introduced in Section 2. For example,

$$
f(z, \gamma)=\left\{\left(z+\gamma_{1}\right)^{3}+\gamma_{2}\right\} /\left\{\left(z+\gamma_{3}\right)^{2}+\gamma_{4}\right\},
$$

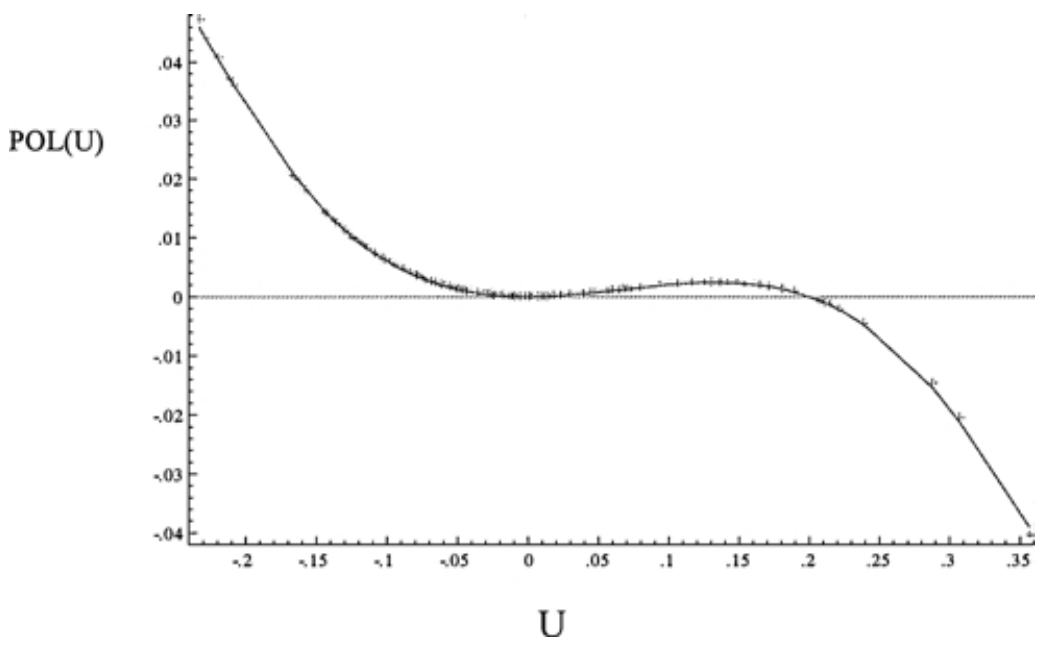

Figure 3. Cubic polynomial in $U_{t}$. 


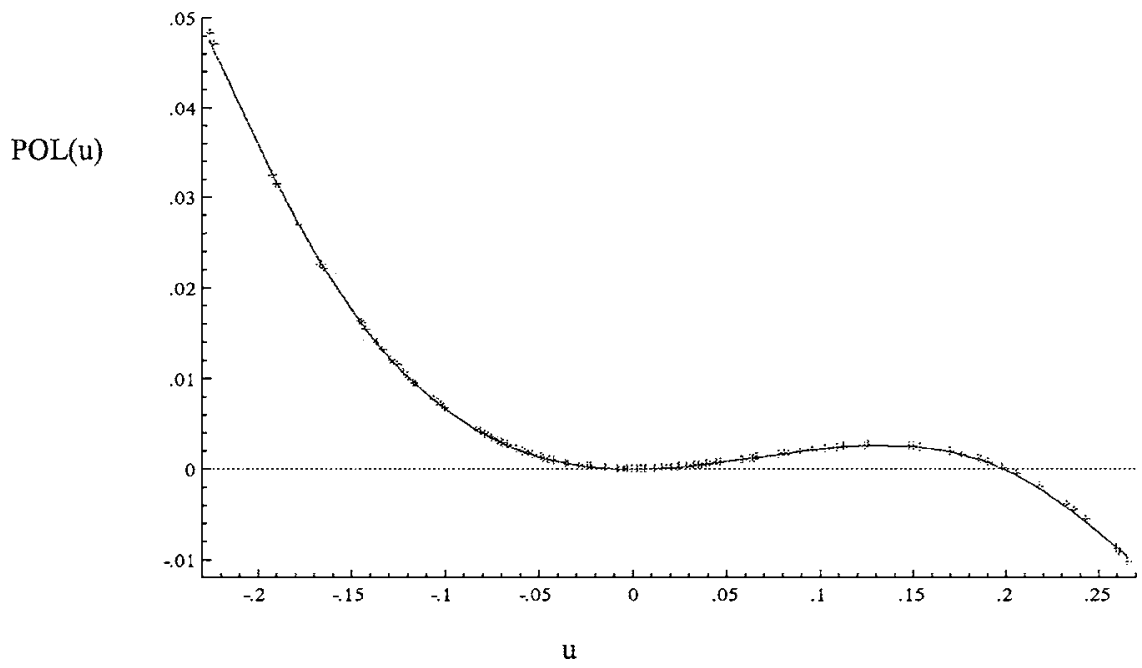

Figure 4. Cubic polynomial in $u_{t}$.

where if $\gamma_{2}=-\gamma_{1}^{3}$ and $\left(\gamma_{3}^{2}+\gamma_{4}\right) \neq 0$, then $f(z=0, \gamma)=0$ is the equilibrium. The adjustment can be asymmetric and/or nonlinear, generalizing Granger and Lee's (1989) asymmetric (piecewise linear) error correction.

If we want the rational polynomials to have multiple equilibria, we might prefer the following functional form:

$$
f(z, \gamma)=\gamma_{0}\left\{\left(z+\gamma_{1}\right)^{3}+\gamma_{2}\right\} /\left\{\left(1 /\left(z+\gamma_{3}\right)^{2}\right)+\gamma_{4}\right\}
$$

where if $\gamma_{2}=-\gamma_{1}^{3}$; then, $f(z=0, \gamma)=0$ and $f\left(z=-\gamma_{3}, \gamma\right)=0$ and $f(z, \gamma) \approx$ 0 for all $z \in\left(0, \gamma_{3}\right)$. Therefore, we could have a continuum of equilibria between 0 and $\gamma_{3}$. Estimates of (18) and (19) are given by models C and D of Table 7. Figures 5 and 6 represent the nonlinear adjustments. It is clear that the adjustment is faster the farther we are from $U=0$, and it is clearly asymmetric. This type of asymmetry is not piecewise linear around a zero threshold point, but is piece wise nonlinear around a set of threshold points around zero.

The equilibrium value (threshold) $U=0.2$ of Figures 3 and 4 has an interpretation in terms of the role that the dummy variable $D 2$ was playing in the linear money-demand equations of Friedman and Schwartz (1982) and Hendry and Ericsson (1983); see column 2 of Table 1. If we run a cointegrating regression with log-inverse velocity of circulation of money on a constant, the dummy $D 2$ and short-run interest rates $\left(R N^{a}\right)$, then the estimated coefficient of $D 2$ is near 0.2 , which corresponds to the positive extreme value (threshold) of the interval of the long-run equilibria obtained by estimating NEC models. 
RATIOPOL(U)

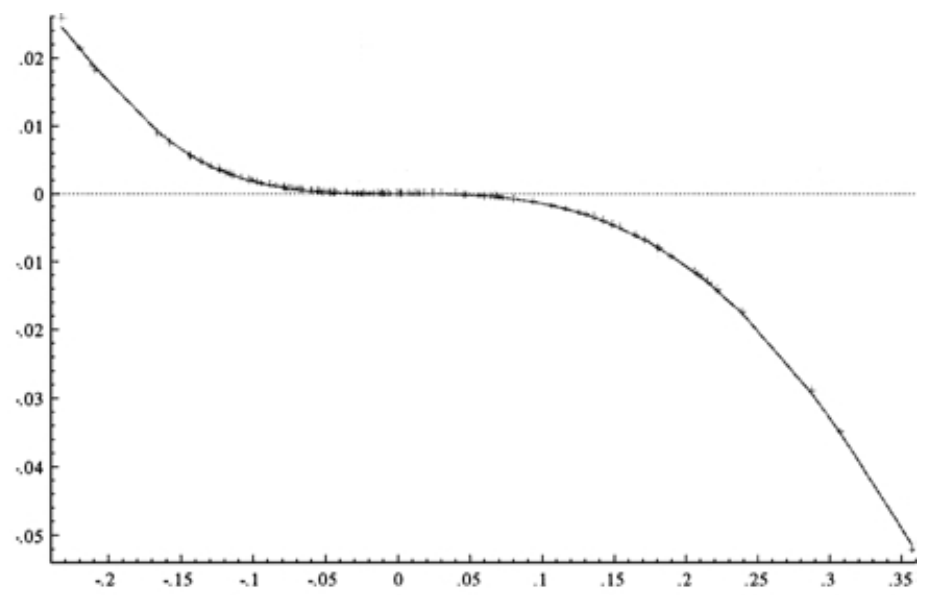

U

Figure 5. Rational polynomial (Model C of Table 7).

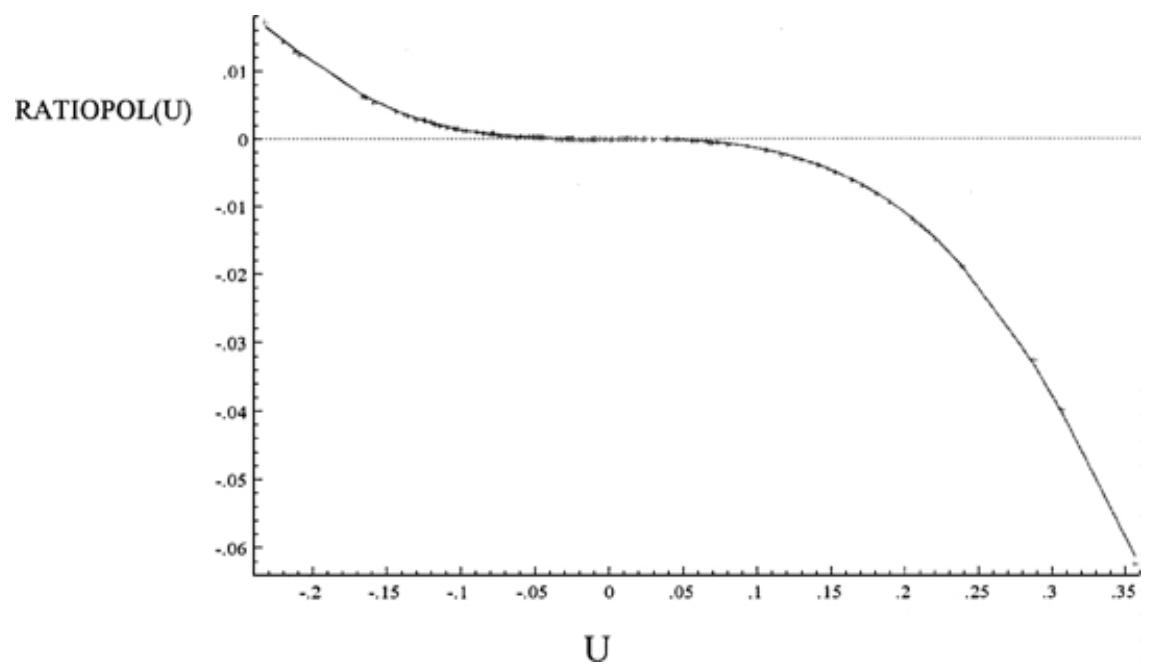

Figure 6. Rational polynomial (Model D of Table 7).

\subsection{Two-Step OLS Estimation of NEC Money Demand (1878-2000) ${ }^{4}$}

The best two-step money demand equation estimated for the period 1878 to 2000 is Model B of Table 7, which is written below as equations (20a) and (20b). In what follows, we will evaluate this econometric specification in terms of the stability 
of the parameter estimates as well as other possible sources of misspecification (autocorrelation, heteroskedasticity, normality, functional form, etc.).

The actual values of $(m-p)_{t}$ and the corresponding fitted values are ploted in Figure 7 with satisfactory results for such a long period of time.

Step 1: Nonlinear cointegration relationship:

$$
U_{t}=(m-p-i)_{t}+0.35+6.16 R N_{t}^{a} .
$$

Step 2:

$$
\begin{aligned}
\Delta(m-p)_{t}= & 0.67 \Delta(m-p)_{t-1}-0.24 \Delta(m-p)_{t-2}-0.09 \Delta^{2}(m-p)_{t} \\
& (8.61) \\
- & 0.64 \Delta p_{t}+0.58 \Delta p_{t-1}-0.15 \Delta p_{t-2}-0.04 \Delta_{2} r l_{t} \\
& (15.24) \\
- & 0.03 \Delta_{2} r l_{t-2}-0.02 \Delta r n_{t}^{a}+0.03(D 1+D 3) \\
& (1.95) \\
+ & 0.05 D c_{t}-2.02\left(U_{t-1}-0.2\right) U_{t-1}^{2}+0.01 \mathrm{e}_{\mathrm{LS}, \mathrm{t}}
\end{aligned}
$$

Summary statistics of equation (20b). Absolute values of $t$-ratios are in parentheses under the coefficient estimates, $T=123$ [1878-2000], 14 variables, $R^{2}=0.87$, $100 \sigma=1.61 \% ;$ AR1-2, $F(2,107)=1.93(p$-value $=0.15) ; \operatorname{ARCH}(1), F(1,107)=$ $0.25(p$-value $=0.62)$; normality, $\chi^{2}(2)=0.19(p$-value $=0.91)$; functional forms $X_{i}^{2}, F(24,84)=0.8(p$-value $=0.72) ;$ and $X_{i} * X_{j}, F(85,23)=0.75(p$-value $=$ $0.83)$; RESET, $F(1,108)=0.60(p$-value $=0.43) ; J t=2.35$; and $\operatorname{Var}=0.34$. It is clear that equation (20b) passes all the misspecification tests, including the stability tests of Hansen (1992), (Joint statistic) $J t=2.35$, and (variance statistic) $\operatorname{var}=0.3$; see Hendry and Doornik (1996) for a detailed explanation of each test statistic.

The stability analysis of the parameter estimates of this NEC model is complemented with a graphical representation of the standardized innovations in the first graph of Figure 8. The second graph plots the one-step residuals with the $0 \pm(S . E)_{t}$. The third graph of the panel plots the one-step Chow statistics normalized by their one-off $1 \%$ critical values. Finally, the last graph represents the breakpoint Chow statistics similarly normalized. The stability of the parameter estimates of the model is clear.

To get stronger support on the empirical constancy of the model, we estimate the main parameters of the model using recursive least squares. The results are included in Figure 9. The eight graphs plot the recursive estimated coefficients plus-or-minus twice the recursively estimated standard errors, and all of the estimated coefficients show a remarkable stability over such a long period of time.

Even if the UK money demand estimated from 1878 to 2000 in equation (20b) behaves satisfactorily, it is possible to get more precise estimates by doing a joint estimation of the short-run and the long-run (cointegration) parameters. This could 


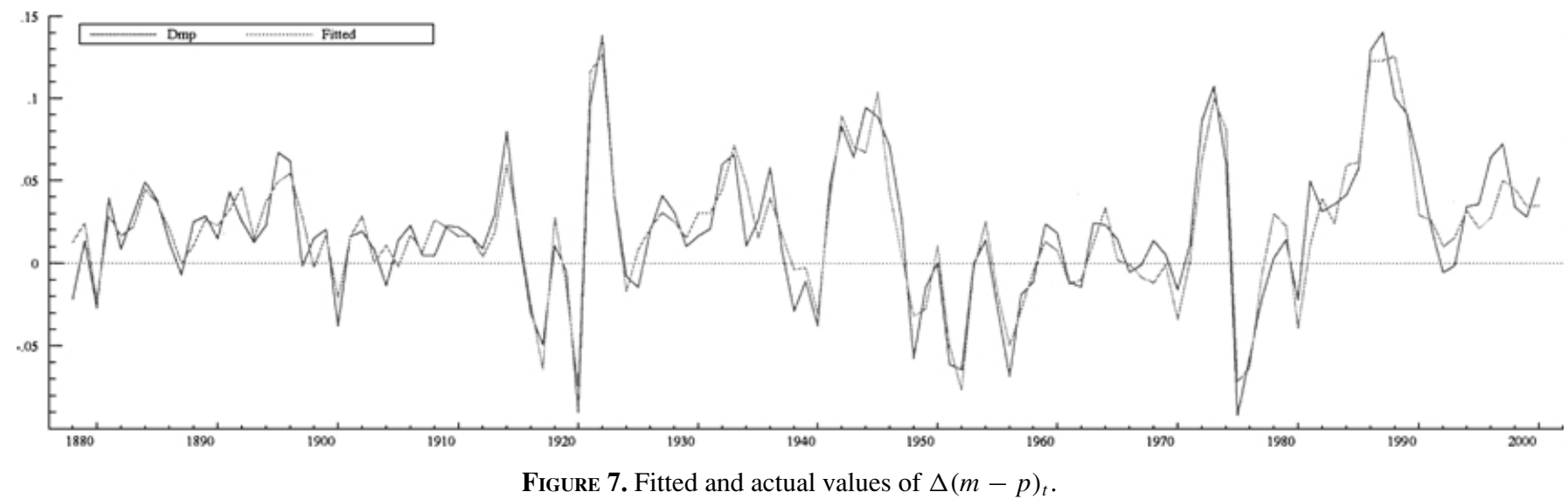

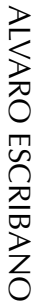

Figure 7. Fitted and actual values of $\Delta(m-p)_{t}$. 

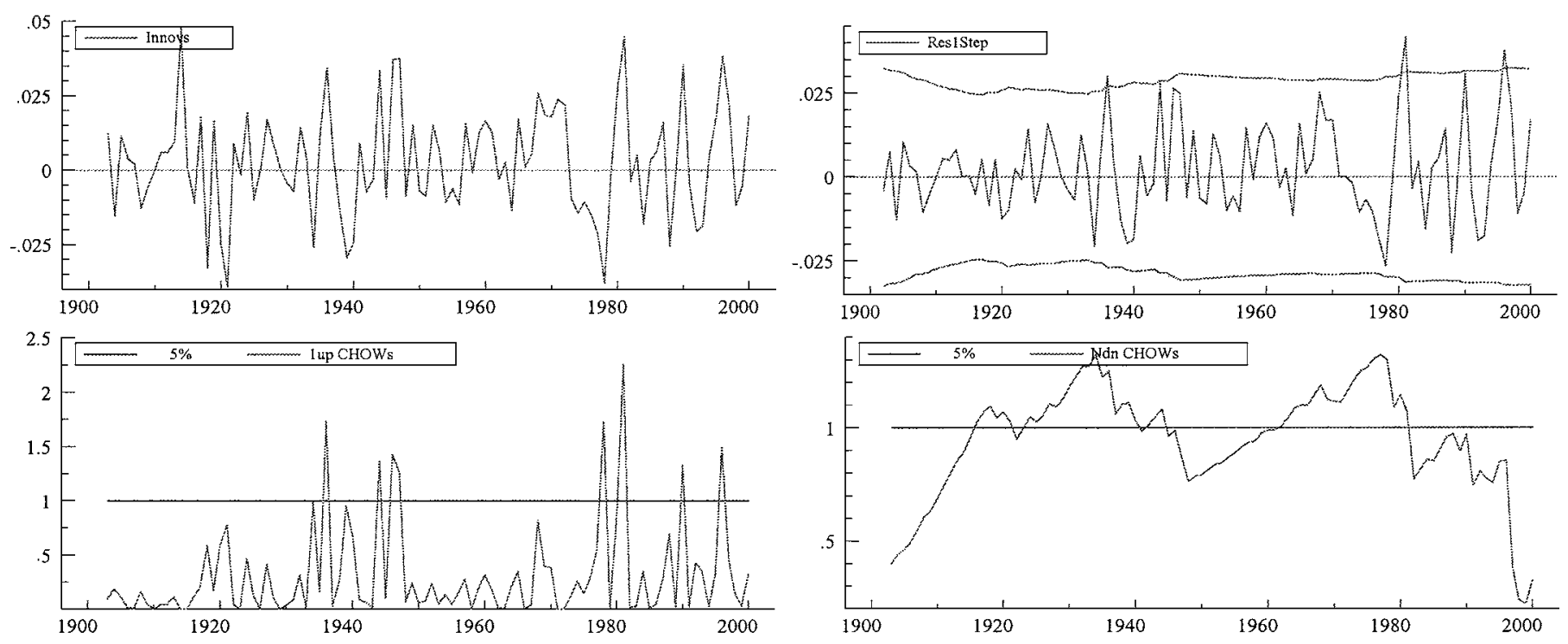

Figure 8. Standardized innovations, one-step residuals, one-step Chow statistics, and breakpoint Chow statistics. 

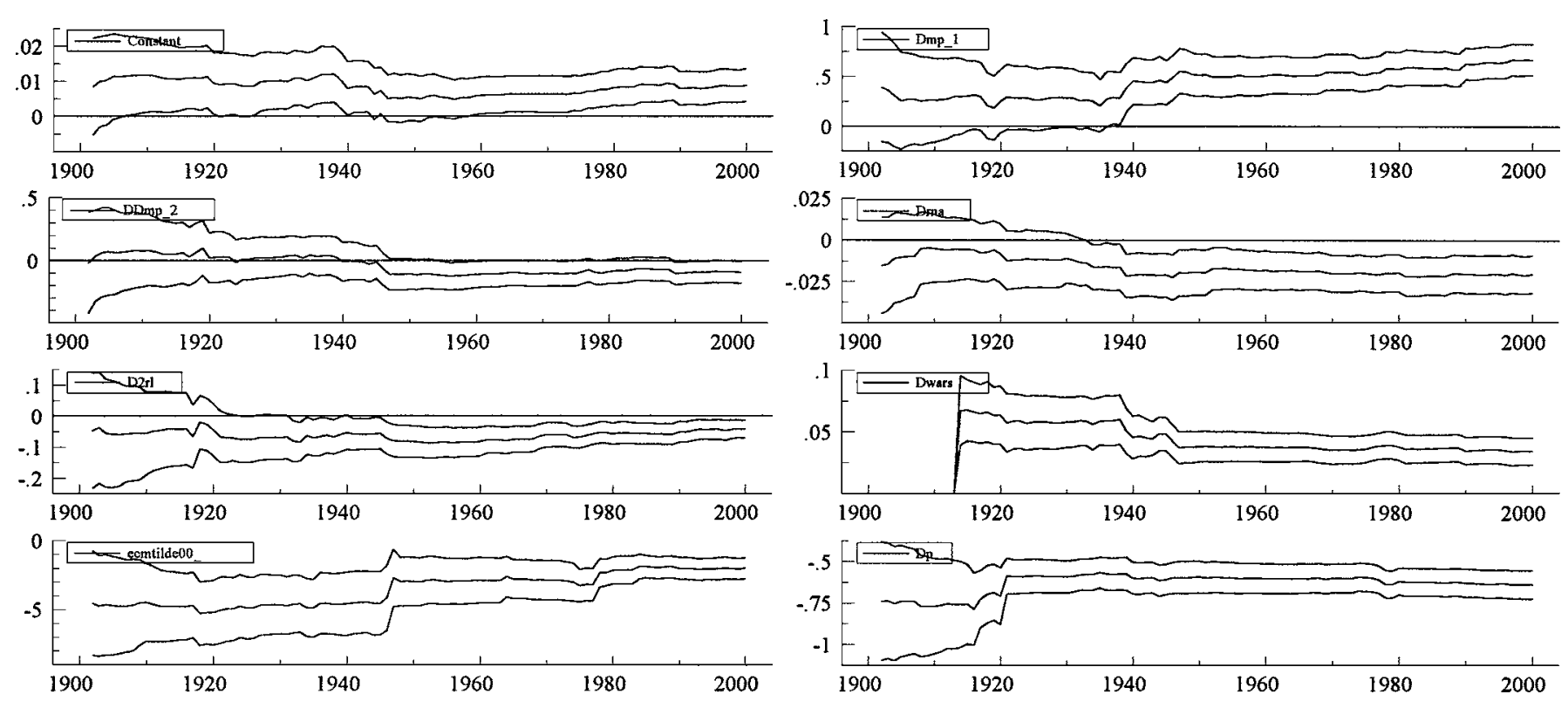

Figure 9. Recursive estimates for coefficients of Model B. 
be especially important for certain types of nonlinearities. To explain this possible source of deviation between the OLS (two-step) and the NLS estimates, we can write equation (1a) as (21b),

$$
\begin{gathered}
y_{t}=\alpha^{\prime} q_{t}+z_{t} \\
z_{t}=\left(b_{0}-\alpha\right)^{\prime} \Delta q_{t}+b_{1}^{\prime} \Delta q_{t-1}+\cdots+b_{r}^{\prime} \Delta q_{t-r}+a_{1} \Delta y_{t-1}+\cdots \\
+a_{p} \Delta y_{t-p}+z_{t-1}+f\left(z_{t-1}, \gamma\right)+\varepsilon_{y t} .
\end{gathered}
$$

Therefore, if the error $z_{t}$ of the cointegrating relationship (21a) has important nonlinearities or breaks [see Campos et al. (1996) and Arranz and Escribano (2000)], then the OLS estimates in (21a) might not be reliable. In those circumstances, we should expect to have more precise estimates from the joint estimation of equations (1a) and (1c) or (20a) and (20b). The empirical NLS results are reported in equations (22a) and (22b) below.

\subsection{One-Step NLS Estimation of NEC Money Demand (1878-2000)}

The model (22b) fits marginally better than the corresponding two-step OLS contempart since the percentage standard error of the regression $(22 b)$ is reduced from $\sigma=1.61 \%$ to $\sigma=1.57 \%$.

This money demand model passes all the misspecification tests done at the 5\% significance level; see the summary statistics included below equation (22b). It is interesting to comment on the important stability of the long-run parameter estimates obtained during very different long time periods. For example, if we compare the coefficients of the cointegrating vectors from the three different periods (1878-1970), (1878-1993), and (1878-2000), the corresponding results are the following: from Table 5, col. 2, we have $\left(1, \alpha_{1}\right)=(1,7.0)$; from Table 6 , col. 5 , we have $\left(1, \alpha_{1}\right)=(1,7.0)$; and from equation (22a), we have $\left(1, \alpha_{1}\right)=(1,7.3)$.

Joint estimation (NLS) of equations (17a) and (17b):

Nonlinear cointegration relationship:

$$
U_{t}=(m-p-i)_{t}+0.16+7.33 R N_{t}^{a}
$$

Nonlinear error correction:

$$
\begin{aligned}
\Delta(m-p)_{t}= & 0.63 \Delta(m-p)_{t-1}-0.23 \Delta(m-p)_{t-2}-0.07 \Delta^{2}(m-p)_{t} \\
& (8.10) \\
- & 0.64 \Delta p_{t}+0.58 \Delta p_{t-1}-0.15 \Delta p_{t-2}-0.04 \Delta^{2} r l_{t}-0.03 \Delta^{2} r l_{t-2} \\
& (15.24) \\
- & 0.02 \Delta r n_{t}^{a}+0.03(D 1+57) \\
& (3.61) \\
- & 2.02\left(U_{t-1}-0.2\right) U_{t-1}^{2}+0.01+\mathrm{e}_{\mathrm{NLS}, \mathrm{t}}
\end{aligned}
$$


Summary statistics of equation (22b): Absolute values of $t$-ratios are in parentheses under the coefficient estimates; $\mathrm{T}=123$ [1878-2000]; 17 variables; $R^{2}=$ $0.87 ; 100 \sigma=1.57 \% ;$ AR1-2, $F(2,104)=2.43(p$-value $=0.09) ; \operatorname{ARCH}(1)$, $F(1,104)=1.21 \quad(p$-value $=0.27) ;$ normality, $\chi^{2}(2)=0.07 \quad(p$-value $=0.96)$; functional forms $X_{i}^{2}, F(29,76)=1.03(p$-value $=0.44)$.

Before concluding, we want to stress the three main issues that we identify as the key elements in order to obtain a parameter constant UK money-demand equation from 1878 to 2000 . The first one is the inclusion of proxies for deregulation. The second one is the fact that we are using the updatted measure of the opportunity cost of holding money, $R N^{a}$, suggested by Ericsson et al. (1998). The difference of this measure with respect to the $R N$ variable used until the year 1970 is clearly seen in Figures B.1 and B.2 of Appendix B. Finally, the third key element for getting parameter constancy is the fact that the equilibrium correction is nonlinear (NEC) around multiple equilibria identified by the interval with two clear threshold extreme values at 0 and 0.2 . The cubic polynomial, $\left(U_{t-1}-0.2\right) U_{t-1}^{2}$, errorcorrection model estimates those threshold values $(0,0.2)$ in a simple and flexible way since the term $U_{t-1}^{2}$ measures deviations from 0 while the term $\left(U_{t-1}-0.2\right)$ measures deviations from 0.2 .

\section{CONCLUSIONS}

In this paper, we study single-equation (NEC) models with linear and nonlinear cointegrated variables. The concepts $I(1)$ and $I(0)$, introduced by Escribano and Mira (1997, 2002), are used to characterize single-equation NEC models. Those concepts replace similar ones introduced by Escribano (1987), based on the concepts of asymptotic uncorrelation and trends in mean and variance. The main advantages of these new definitions are that they have associated laws of large numbers and central limit theorems and therefore allow us to obtain the asymptotic distribution of the least-squares estimators, and to test the null hypothesis of $I(0)$.

We have proposed an econometric methodology to specify NEC models in the context of parametric and semiparametric error-correction models. By using the database of Friedman and Schwartz (1982) and Ericsson et al. (1998) but extended until the year 2000, we implement this econometric methodology to specify a NEC model for money demand for the United Kingdom. Within the class of parametric models, we discuss the properties of the cubic polynomial NEC models introduced by Escribano (1985) and used later by Hendry and Ericsson (1991), Ericsson et al. (1998), Escribano and Granger (1998), and Escribano and Pfann (1998). We recommend the use of cubic polynomials because (i) they represent a very flexible functional form, (ii) they can be estimated by OLS or NLS, (iii) they can be justified as LM tests for nonlinearity, (iv) they can be used to estimate two threshold points in asymmetric NEC models, and (v) they can be used to check the stability properties of the long-run equilibrium estimates.

A new class of rational polynomial NEC models is introduced because it maintains all the previous desirable properties of cubic polynomial adjustments and can 
be specified so that the stability conditions of the nonlinear equilibrium correction are imposed while the function need not be bounded by a constant as in the logistic or exponential specifications. The generality of the rational polynomials is justified in terms of Padé approximants.

Within the class of semiparametric NEC models, we suggest and implement an econometric methodology estimating money demand of the United Kingdom by smoothing splines. The empirical estimates of the money demand using the optimal value of the smoothing parameter, obtained by generalized cross validation, confirms the following final conclusions: The two threshold points are around 0 and 0.2 ; the nonlinear adjustments are asymmetric; both cubic polynomials and low-order rational polynomials are good in sample parametric approximations to the unknown nonlinear and asymmetric error corrections; the existence of longrun multiple equilibria is a likely empirical possibility; and, finally, the in-sample nonlinear adjustment is globally stable, except maybe in the interval 0 and 0.2 , where the adjustments might be either insignificant or unstable.

In the empirical section we found certain cases within this class of rational polynomials that are consistent with having a money demand with multiple longrun equilibria between 0 and 0.2 and having an asymmetric NEC adjustment around the two threshold equilibrium points.

Constant parameter estimates in money demand models is a major issue in empirical studies, as was documented by Laidler (1969), Judd and Scadding (1982), and Goldfeld and Sichel (1990). Our final UK money demand estimates from 1878 to 2000 based on the initial specification by Ericsson et al. (1998) is constant in the parameters and satisfies all the misspecification tests done. Two important aspects of this specification are worth mentioning. The first one is the inclusion of proxies for deregulation and the use of an updated measure of the opportunity cost of holding money, $R N^{a}$. The second key element for getting parameter constancy is the fact that the equilibrium correction is nonlinear (NEC) around multiple equilibria.

The class of smooth-transition regression (STR) models could encompass NEC models if we extend the usual STR framework to allow for the variables to be nonstationary and cointegrated and for the nonlinear function to be unbounded. These are interesting extensions of STR models but are incompatible with the usual fundamental assumptions that require the variables to be stationary and geometrically ergodic; see Tong (1990) and Granger and Teräsvirta (1993). The present approach based on Escribano and Mira $(1997,2002)$ [see also Dufrénot and Mignon (2002)] overcomes this problem. However, this question is beyond the scope of this paper and we are currently working on an the extension of Teräsvirta and Eliasson (2001) by applying STR models to the UK money demand since 2000.

\section{NOTES}

1. The equilibrium correction terminology was introduced by Hendry (1995, p. 213) and implicitly assumes that the adjustment toward the equilibrium is stable [see condition (iv) of Theorem 1], which is a very important restriction in nonlinear models. 
2. Since $q_{t}$ is an $I(1)$ vector we assume that all its elements are $I(1)$ and not cointegrated. This is what Escribano and Peña (1994) called a jointly $I(1)$ vector.

3. The variable $\Delta_{2} r l_{t-2}$ was dropped in Model A since it was not significant. However, this variable is important when the short-run interest rate is specified in levels (not in logs) in the cointegration relationship; see Models B, C, and D of columns 3, 4, and 5, respectively, of Table 7.

4. These estimation results and the misspecification test done with equations (20a) to (20b) were computed using PcGive 9.0; see Hendry and Doornik (1996).

\section{REFERENCES}

Arranz, M.A. \& A. Escribano (2000) Cointegration testing under structural breaks: A robust extended error correction model. Oxford Bulletin of Economics and Statistics 62, 23-52.

Attfield, C.L.F., D. Demery \& N.W. Duck (1995) Estimating the UK Demand for Money Function: A Tests of Two Approaches. Discussion paper 95/404, University of Bristol.

Baker, G.A. \& P. Graves-Morris (1996) Padé approximants. Encyclopedia of Mathematics and Its Applications, 2nd ed. Cambridge, UK: Cambridge University Press.

Banerjee, A., J.J. Dolado, D.F. Hendry \& G.W. Smith (1986) Exploring equilibrium relationships in econometrics through static models: Some Monte Carlo evidence. Oxford Bulletin of Economics and Statistics 48, 253-277.

Banerjee, A., J.J. Dolado, J.W. Galbraith \& D.F. Hendry (1993) Cointegration, Error Correction and the Econometric Analysis of Nonstationary Data. Oxford: Oxford University Press.

Campos, J., N. Ericsson \& D.F. Hendry (1996) Cointegration tests in the presence of structural breaks. Journal of Econometrics 70, 187-220.

Davidson, J. (1994). Stochastic Limit Theory. New York: Oxford University Press.

Davidson, J., D.F. Hendry, F. Srba \& S. Yeo (1978) Econometric modelling of the aggregate time-series relationship between consumer's expenditure and income in the United Kingdom. Economic Journal $88,661-692$.

Dufrénot, G. \& V. Mignon (2002) Recent Developments in Nonlinear Cointegration with Applications to Macroeconomics and Finance. Boston: Kluwer Academic.

Engle, R.F. \& C.W.J. Granger (1987) Cointegration and error correction: Representation, estimation and testing. Econometrica 55, 251-276.

Engle, R.F., C.W.J. Granger, J. Rice \& A. Weiss (1986) Semiparametric estimates of the relationship between weather and electricity sales. Journal of the American Statistical Association 81, 310-320.

Ericsson, N.R., D.F. Hendry \& K.M. Prestwich (1998) The demand for broad money in the United Kingdom, 1878-1993. Scandinavian Journal of Economics 100, 289-324.

Escribano, A. (1985) Non-linear Error-Correction: The Case of Money Demand in the UK (1878-1970). Mimeo, University of California at San Diego.

Escribano, A. (1986) Identification \& Modelling of Economic Relationships in a Growing Economy, Ch. IV. Ph.D. Dissertation, University of California at San Diego.

Escribano, A. (1987) Error-Correction Systems: Nonlinear Adjustments to Linear Long-Run Relationships. Discussion paper 8730, CORE.

Escribano, A. (1996) Non-linear Error-Correction: The Case of Money Demand in the UK (1878-1970). Working paper 96-55 (24), Universidad Carlos III de Madrid.

Escribano, A. \& C.W.J. Granger (1998) Investigating the relationship between gold and silver prices. Journal of Forecasting 17, 81-107.

Escribano, A. \& O. Jorda (1999) Improved testing and specification of smooth transition regression models. In P. Rothman (ed.), Nonlinear Time Series Analysis of Economic and Financial Data, pp. 289-320. Boston: Kluwer Academic Press.

Escribano, A. \& O. Jorda (2001) Testing nonlinearity: Decision rules for selecting between logistic and exponential STAR models. Spanish Economic Review 3, 193-209.

Escribano, A. \& S. Mira (1996) Nonlinear Cointegration and Nonlinear Error Correction. Working paper 96-54 (23), Universidad Carlos III de Madrid. 
Escribano, A. \& S. Mira (1997) Nonlinear Error Correction Models. Working paper 97-26 (13), Universidad Carlos III de Madrid.

Escribano, A. \& S. Mira (2002) Nonlinear error correction models. Journal of Time Series Analysis 23, 509-522.

Escribano, A. \& D. Peña (1994) Cointegration and common factors. Journal of Time Series Analysis $15,577-586$.

Escribano, A. \& G. Pfann (1998) Nonlinear error correction, asymmetric adjustment and cointegration. Economic Modelling 15, 197-216.

Feinstein, C.H. (1972). National Income, Expenditure and Output of the United Kingdom, 1855-1965. Cambridge: Cambridge University Press.

Friedman, M. \& A. Schwartz (1982) Monetary Trends in the United States and the United Kingdom: Their Relation to Income, Prices and Interest Rates, 1867-1975. Chicago: University of Chicago Press.

Friedman, M. \& A. Schwartz (1991) Alternative approaches to analyzing economic data. American Economic Review 81, 39-49.

Gallant, A.R. \& H. White (1988) A Unified Theory of Estimation and Inference for Nonlinear Dynamic Models. New York: Basil Blackwell.

Goldfeld, S.M. \& D.E. Sichel (1990) The demand for money. In B.M. Friedman \& F.H. Hahn (eds.), Handbook of Monetary Economics, Vol. 1, Ch. 8, pp. 299-356. Amsterdam: North-Holland.

Gonzalo, J. (1994) Five alternative methods of estimating long-run equilibrium relationships. Journal of Econometrics 60, 203-233.

Granger, C.W.J. (1995). Modelling nonlinear relationships between extended memory variables. Econometrica 63, 265-279.

Granger, C.W.J. \& T.H. Lee (1989) Investigation of production, sales and inventory relationships using multicointegration and non-symmetric error correction models. Journal of Applied Econometrics 4, $145-159$.

Granger, C.W.J. \& T. Teräsvirta (1993) Modelling Nonlinear Economic Relationships. New York: Oxford University Press.

Granger, C.W.J., F.C. Huynh, A. Escribano \& C. Mustafa (1984) Computer investigation of some nonlinear time series models. In Proceedings of the Conference on Interface Between Statistics and Computing.

Hansen, B.E. (1992) Testing for parameter instability in linear models. Journal of Policy Modeling 14, 517-533.

Härdle, W. \& O. Linton (1994) Applied nonparametric methods. In Handbook of Econometrics, Vol. IV, Ch. 38, pp. 2297-2339.

Harris, D. \& B. Inder (1994) Test of the null hypothesis of cointegration. In C.P. Hargreaves (ed.), Nonstationary Time Series Analysis and Cointegration, pp. 133-152.

Hendry, D.F. (1995) Dynamic Econometrics. Oxford : Oxford University Press.

Hendry, D.F. \& J.A. Doornik (1996) Empirical Econometric Modelling Using PcGive Professional 9.0 for Windows. London: International Thompson Business Press.

Hendry, D.F. \& N. Ericsson (1983) Assertion Without Empirical Basis: An Econometric Appraisal of "Monetary Trends in the ... United Kingdom" by Milton Friedman and Anna Schwartz in Monetary Trends in the United Kingdom. Paper 22, pp. 45-101 (with additional references), Bank of England Panel of Academic Consultants.

Hendry, D.F. \& N. Ericsson (1991) An econometric analysis of the UK money demand in "Monetary Trends in the United States and the United Kingdom" by Milton Friedman and Anna Schwartz. American Economic Review 81, 8-38.

Hendry, D.F. \& G.E. Mizon (1978) Serial correlation as a convenient simplification, not a nuisance: A comment on a study of the demand for money by the Bank of England. Economic Journal 88, 549-563.

Hendry, D.F. \& J.F. Richard (1983) The econometric analysis of economic time series. International Statistical Review 51, 111-163. 
Herrndorf, N. (1984) A functional central limit theorem for weakly dependent sequences of random variables. Annals of Probability 12, 141-153.

Johansen, S. (1992) Cointegration in partial systems and the efficiency of single-equation analysis. Journal of Econometrics 52, 389-402.

Johansen, S. (1995) Likelihood-Based Inference in Cointegrated Vector Autoregressive Models. Oxford: Oxford University Press.

Judd, J.P. \& J.L. Scadding (1982) The search for a stable money demand function: A survey of the post-1973 literature. Journal of Economic Literature 20, 993-1023.

Kwiatkowski, D., P.C.B. Phillips, P. Schmidt \& Y. Shin (1992) Testing the null hypothesis of stationarity against the alternative of a unit root. Journal of Econometrics 54, 159-178.

Laidler, D.E.W. (1969) The Demand for Money: Theories and Evidence. Scranton, PA: International Texbook.

Lo, A.W. (1991) Long-term memory in stock market prices. Econometrica 59, 1279-1313.

Longbottom, A. \& S. Holly (1985) Econometric Methodology and Monetarism: Professor Friedman and Professor Hendry on the Demand for Money. Discussion paper 131, London Business School.

Marmol, F., A. Escribano \& F. Aparicio (2002) Instrumental variable interpretation of cointegration with inference results for fractional cointegration. Econometric Theory 18, 646-672.

Phillips, A.W. (1954) Stabilization policy in a closed economy. Economic Journal 64, 290323.

Phillips, A.W. (1957) Stabilization policy and the time-forms of lagged responses. Economic Journal 67, 265-277.

Phillips, P.C.B. (1987) Time series regression with a unit root. Econometrica 55, $277-301$.

Phillips, P.C.B. (1991) Optimal inference in cointegrating systems. Econometrica 59, $283-306$.

Phillips, P.C.B. \& B.E. Hansen (1990) Statistical inference in instrumental variable regression with I (1) Processes. Review of Economic Studies 57, 99-125.

Phillips, P.C.B. \& M. Loretan (1991) Estimating long-run economic equilibria. Review of Economic Studies 59, 407-436.

Rosenblatt, M. (1978) Dependence and asymptotic independence for random processes. In M. Rosenblatt (ed.), Studies in Probability Theory. Washington, D.C.: Mathematical Association of America.

Sargan, J.D. (1964) Wages and Prices in the United Kingdom: A Study in Econometric Methodology. In P.E. Hart, G. Mills \& J.K. Whitaker (eds), Econometric Analysis for National Economic Planning, Colston Papers, Vol. 16.

Scott, A. (1996) Consumption Credit Crunches and Financial Deregulation. Applied Economics Discussion paper 181, University of Oxford.

Shin, Y. (1994) A residual based test for the null of cointegration against the alternative of no cointegration. Econometric Theory 10, 91-115.

Silverman, B.W. (1985) Some aspects of the spline smoothing approach to nonparametric regression curve fitting. Journal of the Royal Statistical Society Series B 47, 1-52.

Stock, J.H. (1987) Asymptotic properties of least Squares estimation of cointegrating vectors. Econometrica 55, 1035-1056.

Teräsvirta, T. (1994) Specification, estimation and evaluation of smooth transition autoregressive models. Journal of the American Statistical Association 89, 208-218.

Teräsvirta, T. \& A.C. Eliasson (2001) Non-linear error correction and the UK demand for broad money, 1878-1993. Journal of Applied Econometrics 16, 277-288.

Tong, H. (1990) A Dynamic System Approach. Oxford, UK: Oxford University Press.

Tsay, R.S. (1986) Non-linearity tests for time series. Biometrica 73, 461-466.

Wahba, G. (1975) Smoothing noisy data with spline functions. Num. Math., 24, 63-75.

White, H. (1984) Asymptotic Theory for Econometricians. Orlando, FL: Academic Press, Inc.

Wooldridge J. \& H. White (1988) Some invariance principles and central limit theorems for dependent heterogeneous processes. Econometric Theory 4, 210-230. 


\section{APPENDIX A}

DEFINITION A.1 ( $\alpha$-MIXING). Let $v_{t}$ be a sequence of random variables. Let $\Im_{s}^{t} \equiv$ $\sigma\left(v_{s}, \ldots, v_{t}\right)$ and define

$$
\alpha_{m} \equiv \sup _{t} \sup _{A \in \mathfrak{S}^{t}-\infty, B \in \mathfrak{I}_{t+m}^{\infty}|\operatorname{Prob}(A \cap B)-\operatorname{Prob}(A) \operatorname{Prob}(B)| .}
$$

Then $v_{t}$ is $\alpha$-mixing (strong-mixing) if and only if $\alpha_{m} \rightarrow 0$ as $m \rightarrow \infty$.

DEFINITION A.2 ( $\phi$-NED). Let $v_{t}$ be a sequence of random variables with $E\left(v_{t}^{2}\right)<\infty$ for all $t$ and define

$$
\phi_{m} \equiv \sup _{t}\left|v_{t}-E_{t-m}^{t+m}\left(v_{t}\right)\right|_{L 2},
$$

where $E_{t-m}^{t+m}\left(v_{t}\right)=E\left(v_{t} / \eta_{t-m}, \ldots, \eta_{t+m}\right)$ and $|\cdot|_{L 2}=E^{1 / 2}|\cdot|^{2}$. Then, $v_{t}$ is $\phi$-near epoch dependent $(\phi-N E D)$ on an $\alpha$-mixing sequence $\eta_{t}$ if and only if $\phi_{m} \rightarrow 0$ as $m \rightarrow \infty$.

Proof of Theorem 1. For $X_{t}$ to be $I(1)$ both $y_{t}$ and $q_{t}$ must be $I(1)$. By equation (1b), it is clear that $\Delta q_{t}$ is $\phi$-NED on the $\alpha$-mixing sequence $\varepsilon_{q t}$ and therefore it is $I(0)$. Assuming, without loss of generality, that $p<r$, and adding and subtracting $\alpha^{\prime} \Delta q_{t}$ from (1a), we get

$$
\begin{aligned}
& \Delta z_{t}=a_{1} \Delta z_{t-1}+\cdots+a_{p} \Delta z_{t-p}+\left(b_{0}^{\prime}-\alpha^{\prime}\right) \Delta q_{t}+\left(b_{1}^{\prime}+\alpha^{\prime}\right) \Delta q_{t-1}+\cdots \\
& \quad+\left(b_{1}^{\prime}+\alpha^{\prime}\right) \Delta q_{t-r}+f\left(z_{t-1}, \gamma\right)+\varepsilon_{y t} .
\end{aligned}
$$

Provided that condition (ii) is satisfied, the order of integration of $z_{t}$ is not $I(2)$ or higher because even if $f\left(z_{t-1}, \gamma\right)=0$ in (A.1), $z_{t}$ is at most $I(1)$. Therefore, $z_{t}$ could be $\phi$-NED or $I(1)$ depending on $f\left(z_{t-1}, \gamma\right)$. Under assumption (ii), the order of integration of $z_{t}$ from (A.1) is the same as the order of integration of

$$
\Delta z_{t}=\left(b_{0}^{\prime}-\alpha^{\prime}\right) \Delta q_{t}+\left(b_{1}^{\prime}+\alpha^{\prime}\right) \Delta q_{t-1}+\ldots+\left(b_{1}^{\prime}+\alpha^{\prime}\right) \Delta q_{t-r}+f\left(z_{t-1}, \gamma\right)+\varepsilon_{y t} .
$$

From the main theorem of Escribano and Mira (2002), after writing the model (A.2) in companion form and doing some algebra, it is not difficult to show that since $\Delta q_{t}$ is $\phi$-NED on the underlying sequence $\varepsilon_{q t}$, and $\varepsilon_{y t}$ is $\alpha$-mixing, then, under moments condition (v), $z_{t}$ is $\phi$-NED if $-1<\left(d z_{t} / d z_{t-1}\right)<1$.

Part (b) of the theorem requires that $z_{t}$ be $\phi$-NED, and therefore we have to check that this condition on $d z_{t} / d z_{t-1}$ is satisfied. From equation (A.2),

$$
\left(d z_{t} / d z_{t-1}\right)=1+d f\left(z_{t-1}, \gamma\right) / d z_{t-1}
$$

and $-1<\left(d z_{t} / d z_{t-1}\right)<1$ if and only if $-2<d f\left(z_{t-1}, \gamma\right) / d z_{t-1}<0$, which is condition (iv).

Furthermore, from the cointegrating relationship (1c), $y_{t}$ must be $I(1)$ since it is the sum of an $I(1)$ term and a $\phi$-NED term.

Therefore, all the elements of $X_{t}$ are $I(1)$ and $y_{t}$ and $q_{t}$ are cointegrated.

Proof of Theorem 2. See Theorem 6.5.4 of Baker and Graves-Morris (1996).

Proof of Theorem 3. Immediate from Escribano and Mira (1996) by realizing that a linear function is always Hadamar differentiable. 


\section{APPENDIX B}

\section{B.1. DATA}

$R S: \quad \quad$ UK short-term interest rate (Treasury-Bill rate, fraction p.a.), from [1]-[5].

$R L: \quad \quad$ UK long-term bond rate (fraction p.a.), from [1]-[4].

$R N a$ : Opportunity-cost of holding money measured as $(R S * \mathrm{Ha} / \mathrm{Ma}) / 0.25$, from [9].

$E: \quad \quad$ Sterling Pound/Dollar effective exchange rate, from [1]-[3], [5].

$P$ : $\quad$ UK population corrected for departure of Southern Ireland, from [4] and [7].

IC: $\quad$ UK Nominal Net National Income (IC $=I * P$ ), from [1]-[3], [8].

I: $\quad$ UK Real Net National Income, 1929 prices, from [1]-[3], [8].

$P: \quad$ Implicit Deflator of UK Net National Income, 1929 prices, from [1]-[3], [8].

$M: \quad$ UK money stock, from [1]-[5].

$H: \quad$ UK high-powered money, from [1]-[3], [6].

D1 + D3: Dummies for both world wars (WWI for 1914-1918 and WWII 1939-1945), from [1]-[3].

$D c$ : $\quad$ Dummies for both the period of Financial and Credit Deregulation in UK (first period from 1971 to 1975, and the second period from 1986 to 1989), from [1]-[3], [10].

D4Drs: $\quad$ Product of dummy for first credit deregulation period (1971-1975) and the first differences of the logs of UK short-term interest rate, from [1]-[3].

[1] Friedman and Schwartz (1982).

[2] Attfield et al. (1995).

[3] Ericsson et al. (1998).

[4] Bank of International Settlements (BIS) Database.

[5] Eurostat Database.

[6] Bank of England.

[7] Feinstein (1972).

[8] UK Office of National Statistics (ONS).

[9] Hendry and Ericsson (1991).

[10] Scott (1996).

All the data are rescaled as in Hendry and Ericsson $(1983,1991)$ and Ericsson et al. (1998) to compensate for the Southern Ireland effect, 1861-1919. See Friedman and Schwartz (1982, pp. 110-121).

\section{B.2. MEASURES OF MONEY}

UK money stock: Because of the changes in the institutional framework and in the definitions of monetary aggregates (M2, M3, and M4), we do not have a single measure of money. Therefore, our money stock has been constructed using M2 money data from Friedman and Schwartz, from 1878 to 1967 ; from 1968 to 1986 we have used M3 rescaled, and from 1987, M4 rescaled.

UK high-powered money: Attfield et al. (1995) spliced M0 onto Friedman's and Schwartz's measure of high-powered money $\mathrm{H}$ in 1975. 


\section{B.3. OPPORTUNITY COST OF HOLDING MONEY}

We use two different measures of the opportunity cost of holding money. $R S$ is the shortterm interest rate. Friedman and Schwartz (1982) used a fraction of $R S$, denoted $R N$ and calculated as $(H / M) * R S$. This implies that all components of $M$ except for high-powered money $H$ earn interest at the rate $R S$. If $H / M$ were nearly constant, the results would be unaltered. However, as Ericsson et al. (1998) showed, the results are little affected by the election of interest rate, and neither $R S$ nor $R N$ is a good proxy for the opportunity cost. Therefore, they propose to use $R N^{a}$ as an alternative measure of the opportunity cost, defined as $R N^{a}=R S *\left(H^{a} / M^{a}\right) / 0.25$, whereas $H^{a}$ and $M^{a}$ denote actual values.

Figure B.1 shows the time-series $H / M$ (HM rescaled for definitional changes in $M$ and $H$ ) and $H^{a} / M^{a}$ (HAMA not rescaled). These ratios are almost identical over the period prior to 1970 . However, from 1970 to 2000 , both measures experience different important drops. As was well explained by Ericsson et al. (1998), the two largest drops occur from the following redefinitions:

- In 1976, when $H$ passed to be high-powered money to M0.

- In 1987, as $M$ switched from $M 3$ to $M 4$.

The principal difference between $H / M$ and $H^{a} / M^{a}$ begins in 1970. $H / M$ increases over 1976 to 1978 whereas $H^{a} / M^{a}$ descends. And, from then to the end, they preserve an increasing differential.

$R S$ does not incorporate the institutional and definitional changes, which have happened since 1975. Therefore, Ericsson et al. (1998) proposed $R N^{a}$, called RNA, in Figure B.2, or $R N$ as the most suitable measures of opportunity cost. Figure B.2 plots these time series. They finally chose $R N^{a}$ instead of $R N$ since it better takes into account the changes, since the data are not rescaled.

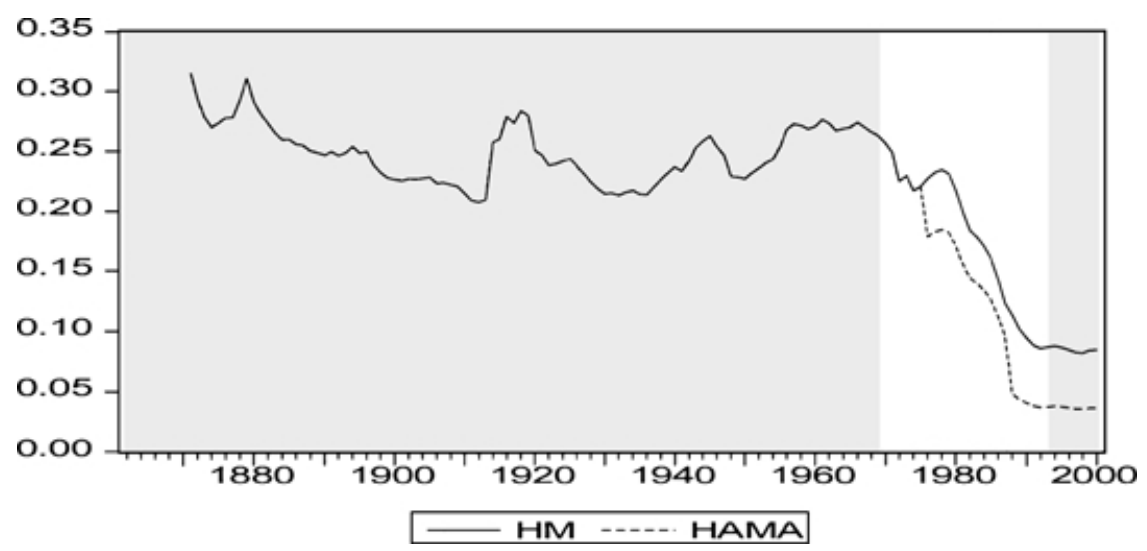

Figure B.1. Plots of $H / M$ and $H^{a} / M^{a}$. 


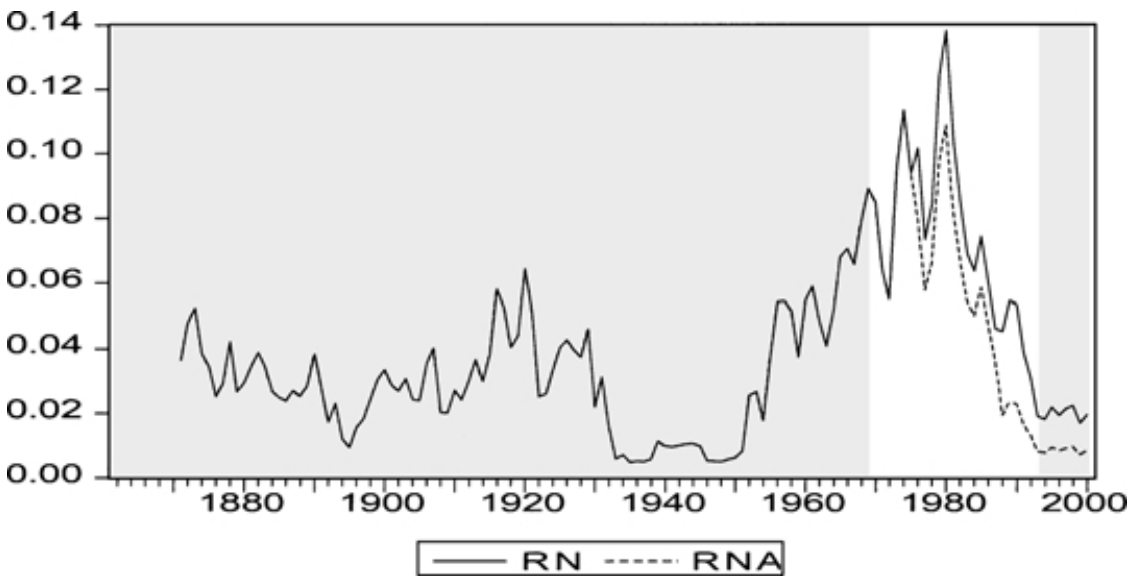

Figure B.2. Plots of $R N$ and $R N^{a}$.

\section{B.4. VARIABLE TRANSFORMATIONS}

Lowercase variables are in $\operatorname{logs}, x=\log (X), r n^{a}=\log \left(R N^{a}\right),(m-p-i)=$ $\log (M / P I)$, etc.

$\Delta_{i} x_{t}=x_{t}-x_{t-i}$

$\Delta x_{t}=x_{t}-x_{t-1}$

$\Delta^{2} x_{t}=\Delta x_{t}-\Delta x_{t-1}$

$U_{t}=$ OLS residuals from the regression of $(m-p-i)_{t}$ on $R N_{t}^{a}$ and a constant (1878-2000)

$U_{t}^{2}=U_{t} U_{t}$

$U_{t}^{3}=U_{t}^{2} U_{t}$

$u_{t}=$ OLS residuals from the regression of $(m-p-i)_{t}$ on $r n_{t}^{a}$ and a constant (1878-2000)

$u_{t}^{2}=u_{t} u_{t}$

$u_{t}^{3}=u_{t}^{2} u_{t}$

$D\left(U_{t}>0\right)=\left(1\right.$ if $U_{t}>0,0$ otherwise $)$

$D\left(U_{t} \leq 0\right)=1-D\left(U_{t}>0\right)$. 